\title{
VAP, a Versatile Access Point for the Endoplasmic Reticulum: review and analysis of FFAT-like motifs in the VAPome.
}

\author{
Sarah E Murphy ${ }^{1}$ and Tim P Levine ${ }^{1 *}$
}

Address:

${ }^{1}$ Department of Cell Biology, UCL Institute of Ophthalmology, 11-43 Bath Street, UK EC1V 9EL

*to whom correspondence should be addressed: tim.levine@ucl.ac.uk

\begin{abstract}
Dysfunction of VAMP-associated protein (VAP) is associated with neurodegeneration, both Amyotrophic Lateral Sclerosis and Parkinson's disease. Here we summarize what is known about the intracellular interactions of VAP in humans and model organisms. VAP is a simple, small and highly conserved protein on the cytoplasmic face of the endoplasmic reticulum (ER). It is the sole protein on that large organelle that acts as a receptor for cytoplasmic proteins. This may explain the extremely wide range of interacting partners of VAP, with components of many cellular pathways binding it to access the ER. Many proteins that bind VAP also target other intracellular membranes, so VAP is a component of multiple molecular bridges at membrane contact sites between the ER and other organelles. So far approximately 100 proteins have been identified in the VAP interactome (VAPome), of which a small minority have a "two phenylalanines in an acidic tract" (FFAT) motif as it was originally defined. We have analyzed the entire VAPome in humans and yeast using a simple algorithm that identifies many more FFAT-like motifs. We show that approximately $50 \%$ of the VAPome binds directly or indirectly via the VAP-FFAT interaction. We also review evidence on pathogenesis in genetic disorders of VAP, which appear to arise from reduced overall VAP levels, leading to ER stress. It is not possible to identify one single interaction that underlies disease.
\end{abstract}

\section{KEY WORDS:}

Amyotrophic Lateral Sclerosis/genetics; Biological Transport; Endoplasmic Reticulum $/{ }^{*}$ metabolism; Intracellular Membranes/*metabolism; Motor Neurons/*metabolism; Vesicular Transport Proteins/genetics/*metabolism

\begin{abstract}
ABBREVIATIONS:
AKAP: A-kinase anchor protein; ALS: Amyotrophic Lateral Sclerosis; CERT: ceramide transfer protein; ER: endoplasmic reticulum; ERAD: ER-associated destruction; FFAT: two phenylalanines in an acidic tract; MSP: major sperm protein; ORP: OSBP-related protein; OSBP: oxysterol binding protein; RdgB: retinal degeneration type B; VAMP: Vesicle-associated membrane protein; VAP: VAMP-Associated Protein; VAPome: VAP interactome.
\end{abstract}

\section{HIGHLIGHTS:}

- Proteins that interact with the ER from outside all interact with VAP.

- VAP has a conserved domain with multiple binding sites for different ligands.

- $\geq 50 \%$ of VAP binders have motifs in the general form of "two phenylalanines in an acidic tract" (FFAT).

- Neurodegeneration is associated with reduced levels of VAP.

- Many myths about VAP pathology result from experiments with over-expression. 
The network of the endoplasmic reticulum (ER) permeates the entire cell and plays a central role for biosynthesis of proteins and lipids. Many vital ER processes are carried out by proteins that are either integrated into the membrane or peripherally associated with it. So far, only one mechanism has been discovered by which peripheral proteins target the cytoplasmic face of the ER: they bind to the integral membrane protein Vesicle-associated membrane protein (VAMP)-Associated Protein (VAP), which is conserved in all eukaryotes. Vertebrates have two VAPs (VAP-A and VAP-B), while the major yeast protein is called Scs2p. VAP is clearly important for cellular function, as mutations in VAP-B cause rare forms of lateonset Spinal Muscular Atrophy and Amyotrophic Lateral Sclerosis-type 8 (ALS8), rare inherited motor neuron diseases [1-4]. Studies of VAP are clinically important because they may explain the pathogenesis of sporadic (non-familial) ALS, a relatively common and devastating disease, and possibly other aspects of neurodegeneration.

In this review we update the sole previous review on VAP [5]. We include individual VAP interactions, and we also analyze data sets from high-throughput proteomic studies. Proteolytically cleaved, secreted products of VAP that act extracellularly are not discussed ${ }^{6}$, 7]. Instead we focus on the intracellular interactions of VAP, which is unique because it interacts with many proteins that are attached to, or even anchored in other compartments. This makes VAP a key player for several different membrane contact sites. These nanometer scale zones specialised for intracellular traffic of material and information have moved center stage in recent years, and a greater understanding of VAP is important for their full understanding.

\section{VAP links the ER to other organelles}

1.1 VAMP-associated by name, but not by nature: VAP consists of a 7-beta strand globular domain in the major sperm protein (MSP) family (120-140 aa), a linker region ( $\leq 100 \mathrm{aa}$ ) partly forming a coiled coil in some species, and a C-terminal transmembrane helix tail anchor that targets the ER (Fig. 1A). VAP was named for its interaction with the SNARE protein VAMP, but although binding to many SNAREs has been reported $[8,9]$, the molecular basis for any such interaction has not been established [10]. Only a minority of protein-protein interaction studies have identified any directly interacting SNARE [11,12], indicating that VAPVAMP binding may only occur under certain lysis conditions. Among SNAREs that bind VAP is the ER SNARE Sec22b [12], which has significant functions at membrane contacts with the plasma membrane [13], so it is important to determine if and how VAP binds Sec22b.

1.2 FFAT, a short motif for proteins to bind VAP: The major set of VAP interactors identified to date are cytoplasmic proteins containing two phenylalanines (FF) in an acidic tract (the FFAT motif). The motif has a core with six defined elements across a stretch of seven residues: $\mathrm{E}^{1}-\mathrm{F}^{2}-\mathrm{F}^{3}-\mathrm{D}^{4}-\mathrm{A}^{5}-\mathrm{x}-\mathrm{E}^{7}$ (using the single letter amino acid code, where $\mathrm{x}$ is any amino acid). This core is supplemented by a seventh, less well defined element: the flanking regions. The immediately adjacent residues (especially upstream) contain multiple acids, but very few basic residues (Fig. 1B) ${ }^{[14]}$. Highly conserved residues in VAP contribute to FFAT binding with a micromolar dissociation constant [15-17]. The FFAT binding site forms an electro-positive face on the major sperm protein globular domain of VAP (Fig. 1A). The critical residues in this binding site have been identified from alanine substitutions as K45, T47 and K118 [15]. Another way to inhibit FFAT binding is to introduce a double charge substitution in residues involved in binding F2: K87D/M89D [16], although alanine mutations show that these two residues are not individually critical for binding [18]. By X-ray crystallography the FFAT motif forms an extended loop that lies across an electro-positive 
face of the globular domain of VAP, the side-chains of $\mathrm{F}^{2}$ and $\mathrm{A}^{5}$ binding into two hydrophobic pockets, and $\mathrm{D}^{4}$ involved in multiple interactions ${ }^{[16]}$. NMR has showed that the interaction is initiated by non-specific electrostatic binding of the acidic tract to the positive surface, and that binding is then cemented by specific interactions in particular by $\mathrm{F}^{2}$ and $\mathrm{A}^{5}$ [17]. The initial non-specific binding is interesting because it implies that any cytoplasmic protein with a long polyacidic (anionic) tract might weakly bind VAP without recognition of specific amino acids.

1.3 VAP interactions at membrane contact sites: Most occurrences of EFFDAxE are in lipid transfer proteins in three families: oxysterol binding protein (OSBP)-related proteins (ORPs), ceramide transfer protein (CERT, also called StARD11), and retinal degeneration-B (RdgB $\alpha$, also called phosphatidylinositol transfer protein-nm proteins 1-3 or Nir1-3) [14]. There are also motifs in: Rab3GAP1 the GEF for Rab18, which regulates ER morphology [19], and the yeast transcription factor 0 pi1p, which regulates phospholipid metabolism [20]. All these proteins function on the ER, and their targeting is mediated by VAP [19-23]. ER targeting by many proteins with FFAT motifs had been overlooked because they have other targeting domains. For example, OSBP targets Golgi membranes with a pleckstrin homology domain, and only inactivation of this reveals underlying ER targeting [24].

Because proteins with FFAT motifs combine this with a second targeting domain, these proteins have a unique cellular role: targeting both the ER and another organelle at the same time ${ }^{[25]}$. This leads FFAT proteins to membrane contact sites, which are places where the ER comes close to (typically 10-30 nm) other organelles, including: the trans side of the Golgi, plasma membrane, mitochondria, endosomes, lysosomes, lipid droplets, peroxisomes, phagosomes and parasitophorous vacuoles. Early electron microscopic studies identified contacts between the ER and other organelles [26], but because the ER extends throughout the cell, and no proteins were known to target contacts, it was assumed that they were random and non-functional. Finding that FFAT proteins target various membrane contact sites has been instrumental in revealing an entire network of intracellular non-vesicular communication that relies heavily on VAP. Membrane contact sites, not all of which include the ER, are discussed comprehensively elsewhere [25, 27-29].

\subsection{Identifying FFAT-like motifs in other VAP interactors using a simple algorithm:}

Apart from the originally defined of FFAT motifs (EFFDAxE), related sequences also bind VAP. Substitutions of all its elements are tolerated [14,17,30,31], so the number of possible variants is extremely large, especially if substitutions are allowed at two or more positions. The natural experiment of evolution provides sequences of homologues of FFAT-positive proteins. In addition, it has been shown that acidic residues cannot substitute for a small neutral residue at position 5 [30], which excludes some potential motifs [32]. Thorough analysis was also carried out for variation at position 1 , which tolerates a wide range of substitutions [30]. Sequences that bound VAP were then used to generate rules to predict the requirements for FFAT-like motifs. This included the understanding that position 3 tolerates considerable variation, which had been predicted from an X-ray study of VAP-FFAT crystals [16] and was supported by work on protrudin, which has a FFAT-like motif with lysine at position 3 [33].

All relevant sequences were used to generate an algorithm executed in Microsoft Excel ${ }^{\mathrm{TM}}$ that scores FFAT-like motifs according to the number of sub-optimal elements, where a "perfect" FFAT motif scores zero (explained in Box 1, and available as Supplementary File 1). A key aspect of this algorithm is deciding how to weight penalties for substitutions of different types at different residues; much information for this decision is still lacking. Nevertheless, application of an early form of the algorithm identified 21 mammalian FFAT-like motifs in cytoplasmic proteins ${ }^{[30]}$. These motifs differ from the original motif mainly at residues $1,3,4$ 
and 7 (Fig. 1C). FFAT-like motifs were also judged on the basis of whether they were conserved across species, and whether they were predicted to be in an unstructured cytoplasmic peptide loop. Six of the proteins with FFAT-like motifs have since been verified to bind VAP (see Table 1) [11], showing that the predictions have some utility, in particular to identify residues for mutagenesis.

An unexpected finding in this field is that ORP3, which has a maximally strong FFAT motif $\left({ }^{450}\right.$ EFFDAQE $^{456}$ score $\left.=0\right)$ has an additional FFAT-like motif $\left({ }^{161}\right.$ HFFSGST $^{167}$ score $=4.5$, 3rd strongest behind ${ }^{318}$ NYSDGSE $^{324}$ score $=4.0$ ) that must be mutated to abolish binding to VAP [34]. This is an important new development, since many VAP interactors have second and even third FFAT-like motifs of this strength (Fig. 1D). Perhaps the evolutionary pressure to bind VAP applies across the whole protein leading to multiple weak FFAT-like motifs. While this has important implications for studying how proteins bind VAP, it also makes it difficult to find all motifs using a tool such as Scan Prosite, which needs a minimal level of complexity to avoid overload [35]. Another advance in this field was the finding that position 3 tolerates an even wider range of substitutions than predicted [10]. We interpret this to mean that any substitution is acceptable at position 3 (see Supplementary Fig. 1).

Overall, defining FFAT-like motifs in silico, although based on incomplete information (Box 1), may be useful for pin-pointing the key residues proteins use to bind VAP.

\subsection{VAP has many interactors, a high proportion of which have FFAT-like motifs} identified by our algorithm: Using an algorithm, can FFAT-like motifs be detected where they have previously been missed? Several proteins that target the ER and interact with VAP were not considered to have FFAT-like motifs ${ }^{[36-39]}$. The algorithm finds FFAT-like motifs in many of these, which might guide future experiments (Fig. 1E). The scores of these motifs varies from 1.0 to 3.5 or more, and there are not enough of them to judge what strength correlates with VAP binding. We therefore decided to analyze sequences of much larger numbers of VAP binding proteins. A successful human VAPome project was included as a small part of the BioPlex interactome network [11]. This found very high numbers of interactors for VAP-A and -B (56 and 75 respectively), with a considerable overlap between them (Table 1A). Excluding a minority of integral ER proteins, there were 86 VAP interactors. 12 of these have FFAT motifs as originally defined (Table 1B). We scanned the remaining 74 proteins $(65,000$ residues in total) for FFAT-like motifs using our algorithm, along with 286 randomly chosen (negative control) proteins $(125,000$ residues). The VAPome contained 24 motifs with less than 3.0 suboptimal elements, and only two motifs of this strength were found in the control data set (Fig. 2A). We therefore decided to set a score of $<3.0$ as a threshold for defining strong FFAT-like motifs with high specificity.

Using this threshold, we predict 24 FFAT-like motifs as sites for experimental investigation to determine how proteins bind VAP (Table 1C). If all these predictions are correct, then they would account for the binding to VAP of 10 other members of the VAPome; these proteins have weak FFAT-like motifs themselves but they also have well-documented interactions with a protein with a FFAT motif or with a strong FFAT-like motif (Supplementary Fig. 2). Thus, a search for FFAT-like motifs produces testable hypotheses about the binding of $46 / 86$ (>50\%) of the VAPome. This is a much higher proportion than previously thought just by applying the original FFAT criteria (14/86, 16\%) [11]. Two additional criteria that have been applied previously [30] (not forming a helix or sheet [40], and phylogenetic conservation [20]) have yet to be applied to these potential FFAT-like motifs. As support for the validity of our predictions, the VAPome and controls were searched for their second strongest FFAT-like motifs. The strength of the second motifs in the interactors with strong FFAT-like motifs was very similar 
to that of the second motifs in proteins with originally defined FFAT motifs (Fig. 2B); by comparison, second motifs in the interactors with weak FFAT-like motifs (score $\geq 3.0$ ) were similar to second motifs in control proteins (Fig. 2B). This segregation of second motifs into two groups suggests that proteins in one group are under evolutionary pressure to bind VAP via FFAT motifs, while proteins in the other group do not interact at all in this way. This indicates that the finding that proteins that bind VAP have multiple binding sites may turn out to be a general feature [34]. However, the single example of the functionally important second motif in ORP3 is so weak that we find currently indistinguishable motifs in $\sim 30 \%$ of control proteins (Fig. 2B). This indicates that although the algorithm shows that second motifs are a general feature, it is unable to detect which second motifs are functionally important.

Compared to humans, the yeast interactome has been studied in great depth over almost 15 years [41,42]. 24 of the 59 protein interactors documented for Scs $2 p$ are cytoplasmic, of which 4 have originally defined FFAT motifs [14]. Applying our algorithm to the rest of the yeast VAPome we found strong-FFAT-like motifs in five of the remaining 20 cytoplasmic proteins (25\%), in none of the 27 membrane proteins, and in one of the 8 lumenal proteins

(Supplementary Fig. 3). Together with the human interactome findings, we suggest that the algorithm can be used to predict key residues for mutagenesis (position 2, possibly combined with 4 or 5 , in strong FFAT-like motifs) in the investigation of VAP binding in any species.

1.6 Cytoplasmic interactors of VAP carry out diverse functions beyond lipid traffic: The VAP interactors with strong FFAT-like motifs identified by BioPlex include human proteins with diverse functions that go well beyond the predominance of lipid transfer found originally in proteins with the FFAT motif [14]. The VAPome contains proteins in other functional categories: cytoskeleton, membrane trafficking, signaling, nucleus (Table 2), as well as functions identified previously in protein insertion into the ER and in ER-associated destruction (ERAD) [10]. For the latter, an extra binding site in VAP has been discovered: two partially conserved acidic residues in a loop at some distance from the main FFAT binding site of VAP partly mediate binding by the FFAT-like motif of FAF1, a ubiquitin-binding adaptor (Fig. 1A) [43]. This finding suggests that multiple elements in VAP modulate overall affinity for binding partners.

An old observation that has yet to be dissected at the molecular level is that VAP binds microtubules [44], and consistent with this the VAPome includes tubulin- $\alpha 1 \mathrm{C}$ [11]. A problem here is that tubulins, particularly their anionic C-termini, are very sticky. Indeed, tubulins are the third most common proteins that contaminate precipitation experiments, appearing in $>90 \%$ of negative controls [45]. In addition, the strong FFAT-like motif at the C-terminus of tubulin- $\alpha 1 C$ ( ${ }^{417}$ EFSEARE $^{423}$, score $\left.=1.5\right)$ is normally hidden by being folded into an alpha helix. However, there may still be occasions when this motif is exposed: the C-terminus of detyrosinated tubulin can be partially unfolded by spastin on sorting endosomes [46], so this process could allow specific access of severed microtubules to VAP at ER-endosomal contacts.

In the VAPome of budding yeast most of the cytoplasmic proteins bind other VAPome members, so some may bind VAP indirectly (Supplementary Fig. 3). This suggests that the five new strong FFAT-like motifs we found could be of some overall significance. Three of these are in proteins that have been studied specifically for FFAT motifs: Pbi1p, Epo1p and Num1p. In each case the strongest motif we find was not identified previously. As in mammalian cells, yeast VAP is implicated in lipid traffic, and Pbi1p is a binding partner of the lipid transfer protein Pdr17p. Although the latter does not bind Scs2p, Pbi1p does [32], and we suggest that this might be mediated by a FFAT-like motif near its C-terminus ( $\left.{ }^{507}{ }^{2} F V E C F E{ }^{513}\right)$. Yeast VAP is also implicated in physical tethering of the cortical ER. Epo1p is a polarisome protein that 
anchors the cortical ER to sites of polarised growth $[47,48]$ and binds to the FFAT-binding site of Scs $2 p$ [47]. The FFAT-like motif ( ${ }^{610}{ }^{2} Y V T A Q E^{616}$, score 2.5) was not previously detected [48], but is in a region that binds tightly to $S \operatorname{cs} 2 p$. The role of this motif might be hard to isolate, since there are many weaker FFAT-like motifs nearby (residues 560-640). A second Scs2p binding site in Epo1p maps to its C-terminal domain (residues 852-943) [48], and this region contains only a weak FFAT-like motif $\left({ }^{859}\right.$ SFDDSSS ${ }^{865}$ score $\left.=4.0\right)$. Num1p links both cortical ER and mitochondria to the plasma membrane [49], and a highly anionic region near its $\mathrm{N}$ terminus was shown to be important for its function and interaction with Scs $2 p{ }^{[47]}$. Although this region might bind Scs2p, it contains no strong motif by our scoring system ( ${ }^{315}$ DIFDIVI $^{321}$ and ${ }^{316}$ IFDIVIE $^{322}$ both score $=6.0$ ). In contrast, there is a strong motif distally $\left({ }^{2134}\right.$ MFTDALD ${ }^{2140}$, score $\left.=2.5\right)$. This shows that either our scoring system is wrong, or the biology of Num $1 \mathrm{p}$ is more complicated than we envisage. In addition to the three new FFATlike motifs described above, we found strong FFAT-like motifs in two other yeast VAPome proteins: Erb1p ( ${ }^{52 E Y E S A V E}{ }^{58}$ ) and Utp9p (566EFVDASE ${ }^{572}$ ). Both Erb1p and Utp9p are involved in ribosomal biogenesis, so although these interactions have yet to be studied directly ${ }^{[42]}$, the motifs could be investigated to see if they underlie the weak nucleolar targeting detected in Scs2p [50].

1.7 Other ways for cytoplasmic proteins to bind VAP: For $>40 \%$ of VAP interactors there is no strong FFAT-like motif, and no binding to another protein that has one (Table 1). Some of these may still bind the conserved globular domain of VAP using other, non-FFAT based binding interactions. A helix in the yeast septin Shs1p binds to a solvent accessible loop separate from the FFAT binding site (Fig. 1A) [47]. A third binding site in VAP that overlaps with the FFAT binding site interacts with unstructured regions of hepatitis $C$ virus proteins, both NS5A [51] and NS5B [52] (Fig. 1A), facilitating viral genome duplication. In both cases, the key properties of VAP interactors have not yet been defined, so it is not possible to say which members of the VAPome, if any, use these binding sites, or whether yet more sites are yet to be discovered.

\section{Interactions within the ER}

In addition to interactions with proteins in the cytoplasm, VAP has many interactions within the ER, though these have only been treated in a fragmented way so far. The best studied intra-ER interaction is dimerization. This involves both the transmembrane helix, which has a GxxxG dimerization motif that is conserved throughout evolution [53], and the coiled coil in the linker region present in some VAPs. The two dimerization domains might combine to produce oligomeric chains, although this is not a prominent feature with native human protein at physiological levels [53]. A further, weaker dimerization occurs between two FFAT motifs that are both binding VAP [16]. Thus, a dimeric protein containing a low affinity variant FFAT-like motif can use the avidity of bivalent interaction with VAP dimers/oligomers to target the ER quite tightly [30,43].

VAP interacts not only with itself, but also with other integral ER membrane proteins. Compared to the human VAPome where $<10 \%$ of interactors are membrane proteins, in yeast $60 \%$ of reported interactors with Scs $2 p$ are integral ER membrane proteins. Many of these interactions may be indirect, as this part of the interactome is highly interconnected (Supplementary Fig. 3). Presumably the network of physical interactions is as dense in humans as it is in yeast, but not yet documented as well, so proteins like derlin could be associated with VAP indirectly through complex formation withFAF1 or BAP31, other proteins involved in ERAD [10,43]. Several intra-ER interactions have been studied in detail including (i) Yet1p in yeast, the homologue of BAP31 [54-56]; (ii) the mammalian ER-stress 
sensing transcription factor ATF6 [43, 57]; (iii) YIF1A involved in membrane traffic pout of the ER [58], and (iv) the phosphoinositide 4-phosphatase Sac1p [59, 60]. Sac1p is intimately involved in communication across contact sites, as hydrolysis of phosphoinositide 4-phosphate is required for lipid countercurrents mediated by ORPs [61]. It is likely that lipid hydrolysis by Sac1 takes place after transfer into the ER, but it is also possible that under some circumstances (e.g. at very narrow contacts) Sac1 could work in trans on lipid embedded in other compartments. This would be facilitated by the interactions that Sac1 makes with both VAP ${ }^{[59]}$ and ORPs ${ }^{[60,62]}$, to potentially make a trimeric VAP-ORP-Sac1 complex. However, Sac1p is not known to concentrate in the cortical ER, so the role of in trans activity at the plasma membrane remains unclear. Another integral ER protein that binds VAP is protrudin, which forms bridges to endosomes all by itself through FYVE and Rab11-binding domains. The VAP interaction is definitely not via the transmembrane helices, as protrudin has a FFAT motif that binds VAP [33]. It has yet to be established how the presence of two anchor points for the ER in protrudin are important for its function, but this the sole known occurrence of a FFAT-motif in an integral ER protein.

Overall, VAP may determine the composition not only of bridges between the ER and other organelles, but it may also determine (at least in part) the local composition of the ER membrane adjacent to bridges.

\section{Function of VAP: a hub for intracellular non-vesicular communication}

VAP binds many proteins outside the ER, including proteins that are anchored by transmembrane helices into mitochondria or endosomes [31,33,37], as well as proteins that bind the plasma membrane [60]. This means that VAP is part of different bridges between the ER and other organelles (Fig. 3). In yeast deletion of Scs2p reduces ER-plasma membrane contacts by $50 \%[18,50]$. The reduction of cortical ER caused by deleting Scs2p, the major yeast VAP, is not augmented by deletion of Scs22p, the minor VAP in yeast [15]. However, a yeast strain constructed to entirely lack three classes of ER-plasma membrane bridging proteins including both Scs2p and Scs22p loses $90 \%$ of ER-plasma membrane contacts [18]. A special role for VAP at contact sites with plasma membrane may arise from its binding to anionic phospholipids such as phosphatidylinositol 4-phosphate, which is enriched in the plasma membrane and late Golgi [63]. In mitochondria VAP binds PTPIP51 (also called RMD3) [64], possibly via two marginal FFAT-like sequences (scores 3.0 and 3.5, Fig. 1E). Without this interaction the extent of contacts between ER and mitochondria is reduced by $30 \%$, indicating that VAP contributes partially to inter-organellar tethering as multiple sites.

Despite the repeated observation that FFAT-containing proteins target contact sites, it is only in plants that VAP is clearly concentrated in contacts [39]. In mammalian cells and yeast, unless binding partners such as CERT are over-expressed [65], VAP is uniformly distributed throughout the ER $[47,66]$. This is a mystery if VAP is a contact site protein, and some advance is needed to better understand VAP distribution. Accumulation of VAP near the Golgi has been interpreted as indicating that VAP recycles through the whole Golgi, as it has been reported to reach the intermediate compartment [67]. However, the VAP does not reach mid-Golgi glycosylation enzymes [68] indicating that its presence near the Golgi is within ER tubules and cisternae that interdigitate with late Golgi membranes [69].

The function of membrane contact sites is to facilitate non-vesicular communication between organelles $[25,27,28]$. The recruitment of many lipid transfer proteins to contact sites suggests, but does not prove, that this is where lipid traffic takes place. The few instances where the 
evidence for lipid traffic at contacts is overwhelming involve lipid transfer proteins with FFAT motifs (Fig. 3) [65, 70-72]. Some organelles elaborated for the replication of intracellular parasites, either bacteria or viruses, recruit lipid transfer proteins and VAP to deliver lipids from the ER [73-75]. VAP also anchors the ER to other organelles for functions other than lipid traffic, especially to organise the cytoskeleton (Fig. 3). $\mathrm{Ca}^{2+}$ traffic is a major contact site function where VAP has no defined role [76], however it is one of the small number of ER proteins enriched at ER-plasma membrane contacts where store-operated $\mathrm{Ca}^{2+}$ entry takes place [77].

\section{VAP dysfunction in neurodegeneration and cellular pathology}

The best studied VAP mutation is VAP-B(P56S), a rare autosomal dominant cause of ALS-type 8 [1]. However, VAP is potentially of general importance in neurodegeneration because low VAP is found in sporadic ALS (80\% control level) [78], and also because another VAP mutation (VAPBAV25) is linked to sporadic Parkinson's Disease [79]. Disease associated with P56S appears to stem from low levels of VAP. The P56S mutation tends to unfold both VAP-A and VAP-B, exposing hydrophobic patches, leading to formation of micro-aggregates that are ubiquitinated and rapidly destroyed [80]. This is particularly important for VAP-B because it is more prone to aggregate than VAP-A, either when overexpressed or when destabilized by ALS-associated mutations in its globular domain or its TMD $[4,66]$. There is some disagreement on whether clearance of VAP-B aggregates is via ERAD and the proteasome (without autophagy) [80], or whether autophagy is involved [81]. Cells from mice with P56S recombined at both VAP-B alleles have hardly any VAPB remaining in the ER [81], and a similar dominant negative mechanism was found for a P56S model of Drosophila VAP [82]. In heterozygotes where P56S is expressed at the correct levels (i.e. not over-expressed), the main pathogenic mechanism appears to be haploinsufficiency [80]. Remaining P56S can have toxic effects through dimerization with WT protein (VAP-A or -B) that are then also cleared. This may explain how P56S homozygosity has a worse effect than a null mutation [81], though degradation of VAP-A has not yet been examined in that system. Thus, heterodimerization may explain how motor neurons induced from pluripotent stem cells carrying the P56S mutation show reduced VAP-B levels below $50 \%$ of control (e.g. $25 \%$ [83]).

Experiments relating to overall reduction in the levels of VAPB (and VAPA) should be compared favourably with a large number of other studies where wild-type or mutant VAP has been over-expressed. This induces several effects: (i) morphological changes in the ER (for example rosettes and stacks) [16], (ii) sequestration of VAP interactors [68], (iii) altered membrane traffic [84], and (iv) block in protein degradation [85], all of which contribute to reduced survival. We question the pathophysiological relevance of any over-expression experiment, since this is not a feature of cells undergoing neurodegeneration. Nevertheless, sequestration by VAP continues to be the subject of experiments, for example to determine which interactors bind to VAP-B differently if it has a disease mutation [11]. A re-analysis of these results in the light of all the strong FFAT-like motifs we describe above might show that differential binding to VAP variants does not correlate with the presence or absence of these motifs. The major message is that ALS8 mutants can bind FFAT motifs [11, 53]. Even if the affinity is affected, the importance of this in pathophysiology is not clear if disease stems from the lack of VAP that is destroyed after it has aggregated.

How does reduced VAP cause disease? One neuron-specific function of VAP is to facilitate delivery by protrudin of a microtubule motor on to endosomes, which then travel to donate membrane to neurites [86]. Another VAP function linked to ALS is the extent of ERmitochondrial contact, which is regulated by TDP-43, another protein implicated in ALS [64]. 
Yet another possible crucial VAP function is destruction of misfolded proteins via ERAD, and VAP has been shown to be important for this [43]. However, VAP has $>100$ known interactors and possibly more will be discovered. So it seems most likely that no single interaction is crucial. Instead, cellular dysfunction is likely to derive from the combined loss of many ERrelated functions, including lipid traffic, membrane traffic, cytoskeleton co-ordination, ERAD and intranuclear functions (Table 2). One place to look for the sum of all these effects is ER stress. Loss of VAP contributes to ER stress including induction of the unfolded protein response in both the yeast and fly models [18, 87], and in human cells [81]. It also may not be that reduced VAP constitutively stresses the ER, but that when stress does arise the ER is less able to induce the UPR [88].

\section{Future directions for VAP research}

If the sub-micron scale of contact sites is ideal for regulating the distribution of small molecules such as $\mathrm{Ca}^{2+}$ and lipids, then maybe other sub-micron functions are organized by VAP at contact sites or other subdomains of the ER. A candidate for such a function is cAMP signalling, which is compartmentalized into sub-micron domains, and organized by A-kinase anchor protein (AKAP) platforms that recruit multiple components of the cAMP pathway and other regulators such as kinases ${ }^{[89]}$. AKAP3 (also called AKAP110, SKIP, and SPKAP) and AKAP11 (also called AKAP220) have FFAT motifs [30]. VAP binding has been verified for AKAP11 [11]. This places cAMP signalling at multiple ER contacts (Fig. 3), the significance of which has yet to be determined.

Another issue is whether human VAP-B has any physiological function that is not shared by VAP-A, excluding any differences only associated with pathology. Current results show a large degree of overlap between VAP-A and VAP-B in their interactions [11] and their intracellular targeting [31]. Their expression patterns are similar across different tissues, including all parts of the brain (see www.gtexportal.org), and even though VAP-B expression is reported to be high in motor neurons, it has not been shown that VAP-A expression is low in the same cells $[81,90]$. One difference that may be significant is that Sac1 binds VAP-A more than VAP-B, making it important to map the VAP-Sac1 binding site [62].

A large task for the future will be to fully catalogue which proteins bind VAP directly, and then to define how binding to VAP affects their other interactions. In all cases, a molecular definition of the residues in both VAP and its interactors will be needed so that the significance of the interaction can be tested. Even though interactions with FFAT motifs appears straightforward, determining how much variation is tolerated in FFAT-like motifs still has to be carried out thoroughly.

\section{SUMMARY:}

VAP plays a major part in ER function, particularly in bridging across contact sites. Most VAP interactors are unstudied, and the roles of their connections to the ER are not known. More functional knowledge of the complete VAPome is needed to determine how VAP dysfunction causes neurodegeneration.

\section{ACKNOWLEDGEMENTS:}

We thank Sean Munro for information on tubulin, Evan Reid for discussions on Spastin, and Catherine Rabouille, Pietro de Camilli and Thierry Galli for helpful suggestions about the manuscript. 


\section{FUNDING:}

SEM is funded by an iCASE award from the BBSRC (BB/L016028). TL is supported by the BBSRC Bioinformatics and Biological Resources Fund (BB/M011801). 


\section{LEGENDS:}

\section{Figure 1: FFAT-like motifs in proteins that bind VAP}

A: Diagram of VAP, a C-terminally membrane anchored protein with three conserved and partly overlapping binding sites on the N-terminal globular MSP domain: (i) electro-positive face (blue) binds EFFDAxE and FFAT-like motifs (red) [15-17] as well as anionic lipids [63]; (ii) base (brown $=$ Scs2p residues equivalent to VAP-A S36 and D37) binds a helix in Shs1p [47]; and (iii) side (magenta = Q6, M89, V90, Q91, D116, L119, and V122 in VAP-A) binds the fuzzy domain of NS5A and the $C$-terminus of NS5B, both from hepatitis $C$ virus (HCV) ${ }^{[51,52]}$. In addition, acidic residues in a loop near the tip (yellow $=$ D77, D79 in VAP-A) contribute to binding by FAF1, a FFAT-positive protein [10,43]. Scale bar $(2 \mathrm{~nm})$ indicates the relative size of the different domains, except two unstructured segments of the linker ( $\leq 8$ and $\leq 13 \mathrm{~nm}$ ) that are not shown. B: Consensus of the flanking regions (10 amino acids both sides) in 14 eukaryotic sequences that contain EFFDAxE. The amino terminal flank is enriched for acidic residues. C: Consensus of the core and flanking regions of 21 predicted FFAT-like motifs [30]. Serines replace acidic residues in multiple positions in the amino-terminal flank, allowing activation by phosphorylation [65, 91]. D: Example of second FFAT-like sequences in proteins with originally defined FFAT motifs; * only the sequence scoring 4.5 in Orp3 has so far been tested ${ }^{34]}$. Other motifs fit the criteria $\mathrm{F} / \mathrm{Y}^{2}, \mathrm{D} / \mathrm{E} / \mathrm{S} / \mathrm{T}^{4}$, and not $\mathrm{D} / \mathrm{E}$ in position 5; all need verification. Note that the additional FFAT-like motifs in OSBP/Osh1p occur at the extreme Cterminus of their lipid transfer domains. Other second motifs shown here are all outside known domains. E: FFAT-like motifs identified in VAP interactors, all human $[10,31,33,36-38,40]$ except NET3C $\ddagger$ from Arabidopsis [39]. Non-conservative substitutions for F/Y ${ }^{3}$ that were previously excluded ${ }^{[30]}$ are highlighted in yellow. * indicates motifs studied before in molecular detail. In $\mathrm{D}$ and $\mathrm{E}$ the number of suboptimal elements was calculated using the algorithm in Box 1, and amino acids are colored by (possible) charge: $\mathrm{D} / \mathrm{E}=$ red, $\mathrm{S} / \mathrm{T}=$ orange, $\mathrm{K} / \mathrm{R}=$ blue.

\section{Figure 2: 24 newly described VAP interactors in BioPlex have strong FFAT-like motifs}

A. The overall strength of originally defined FFAT motifs $(n=12)$ was compared to that of FFAT-like motifs in 74 undefined VAP interactors (the "VAPome") in BioPlex. The graphs show the numbers of suboptimal elements. Also shown are data on the strongest FFAT-like motifs in 286 control proteins. While all the original FFAT motifs score 1.0 or less [14], and controls score on average $4-5$, the VAP interactors have an intermediate score. Using a cutoff of $<3$ suboptimal elements (dashed line, see Table 1), 24 ( $\sim 30 \%)$ VAP interactors were identified as having a strong FFAT-like motif, while less than $1 \%$ of control proteins score this low. B. All sequences from A were scanned for their second strongest FFAT-like motifs. The 12 proteins with originally defined FFAT motifs have strong second FFAT-like motifs. Among the VAP interactors identified in BioPlex, the 24 with strong FFAT-like motifs had second motifs of strength similar to the 12 proteins with originally defined FFAT motifs. In contrast, the 50 proteins with weak FFAT-like motifs had second motifs that were close to those found in controls.

\section{Figure 3: VAP links the ER to several other organelles}

Many functions on the cytoplasmic face of the ER are organised by VAP. Cylinders (hollow if material flows through them) represent separate functional complexes that include VAP; many of these are at membrane contact sites: lipid transfer proteins (blue), with transferred lipid where known [31, 60, 65, 70-72, 91-94] (intracellular parasitophorous vacuoles recruit similar complexes - not shown [73-75]); tethers and cytoskeleton (black) [38,39, 63, 86]; cAMP signaling platforms (green) ${ }^{[95,96]}$; and other ER functions (yellow) ${ }^{[10,97]} . \mathrm{Ca}^{2+}$ traffic also occurs at contacts (red, dashed lines). 


\section{Supplementary Figure 1: FFAT-like motifs found in new VAP interactors}

Sequences of the strongest two FFAT-like motifs (with 6 N-terminal flanking residues) in 86 cytoplasmic VAP interactors from BioPlex ${ }^{[11]}$ listed in Table 1. A. 12 interactors with FFAT motifs as originally defined. B. 74 other cytoplasmic interactors from BioPlex. In each section, interactors are sorted in order of increasing number of suboptimal elements in the FFAT-like motif as defined in Box 1 (i.e. decreasing resemblance to FFAT). Amino acids are colored: D/E - red, S/T - orange, K/R - blue, F/Y (in positions 2/3) - yellow. Potential motifs with nonconservative substitutions for $\mathrm{F}^{3}$ are included on the basis of experimental findings $[10,33]$. The effects of non-conservative substitutions at $\mathrm{F}^{2}$ are not known, and such motifs have been excluded. Note that two extra criteria used previously to eliminate irrelevant motifs (conservation and predicted not to be a helical structure ${ }^{[30]}$ ) have not been applied here.

\section{Supplementary Figure 2: Physical Interactions among the 86 non-ER reported interactors of VAP in humans, and the presence of FFAT motifs}

All 86 non-ER members of the human VAPome in BioPlex ${ }^{[11]}(56,000$ interactions available at wren.hms.harvard.edu/BioPlex/downloadInteractions.php - version 4) were submitted to Genemania.org to identify previously known physical interactions among them, with VAP-A and VAP-B also included (stars). Proteins with an originally defined FFAT motif are indicated by a red background. Proteins with strong FFAT-like motifs are indicated by yellow background. Blue backgrounds indicate proteins that bind to those with either defined or strong FFAT motifs. Heavy black outlines indicates that the VAPome member has been described previously to interact with VAP. Possible binding to Tubulin- $\alpha 1 \mathrm{C}$ (TUBA1C, red outline) is discussed in detail in section 1.5. Details of all predicted FFAT motifs are given in Supplementary Fig. 1. Alternate names and functions of all VAP interactors are given in Supplementary Table 1.

\section{Supplementary Figure 3: Physical Interactions among the 59 reported interactors of VAP in yeast}

All 59 proteins binding yeast VAP (Scs2p) identified in the literature (obtained from the Saccharomyces Genome Database) together with Shs1p and Epo1p ${ }^{[47]}$ were submitted to Genemania.org to identify previously known physical interactions among them, omitting Scs $2 p$ from the network. Only 5 proteins do not interact with any other. 24 soluble proteins (blue outlines) include 4 with FFAT motifs as originally defined (red background) and 5 with strong FFAT-like motifs found by our algorithm (yellow background). All other proteins $(n=35)$ are either integral to membranes with some cytoplasmic domain(s) (black outlines) or largely lumenal (green outlines); a strong FFAT-like motif is found in the lumenal domain of Ost1p (yellow asterisk). Pink backgrounds for Sac1p and Yet1p indicate that they (or their human homologues) are known to interact with Scs2p/VAP via transmembrane helices [54,59]. The physical linkage of most proteins, particularly the integral membrane proteins, into a highly interconnected single network shown by the lines, means that only a minority of these proteins need to bind Scs2 to co-precipitate many others. Note that the FFAT-positive interactors tend to be more peripheral in this physical network (with fewer documented physical interactions), as they bind VAP directly, not indirectly via the network.

\section{Supplementary File 1: FFAT calc workbook}

Up to 30 protein sequences at least 13 residues long (no more than 25,000 residues in total) entered into column E (starting at E12) will be scanned for the four strongest FFAT motifs in each. Only type in boxes with green fill. Sequences pasted in multiple lines into the box A3:A42 will be assembled into a single linear sequence in E3 that is scored in situ, but should be copied out (using Paste Special>Values) into a lower part of column E. The scoring system can be re-weighted by altering the pink squares from AK3:AW23. 


\section{Box 1. Identifying FFAT-like motifs}

FFAT motifs clearly tolerate some substitutions (for example, at the third position [10,33]), but the full range has not yet been tested. Instead we have devised an approximate scoring system, ranking stronger FFAT-like motifs in inverse correlation to the number of suboptimal elements they contain. We scan all possible sequences of 13 amino acids, where the Nterminal 6 residues are the potential acidic tract and the $\mathrm{C}$-terminal 7 residues make up the core motif (see Fig. 1D/E). The total score indicates divergence from canonical FFAT motifs, which score 0 . These scores are updates of those used previously [30] to fit current literature.

\begin{tabular}{|c|c|c|c|c|c|c|c|c|c|c|c|c|c|c|c|c|c|c|c|c|}
\hline & \multicolumn{20}{|c|}{ Amino acid (single letter code) } \\
\hline POS. & A & C & D & $\mathrm{E}$ & $\mathrm{F}$ & G & $\mathrm{H}$ & 1 & $\mathrm{~K}$ & $\mathrm{~L}$ & $M$ & $\mathrm{~N}$ & $\mathrm{P}$ & $Q$ & $\mathrm{R}$ & $S$ & $\mathrm{~T}$ & V & W & Y \\
\hline 1 & 1 & 1 & 0 & 0 & 1 & 1 & 1 & 1 & 1.5 & 1 & 1 & 1 & 1 & 1 & 2 & 0.5 & 0.5 & 1 & 1 & 1 \\
\hline 2 & 4 & 4 & 4 & 4 & 0 & 4 & 4 & 4 & 4 & 4 & 4 & 4 & 4 & 4 & 4 & 4 & 4 & 4 & 2 & 0.5 \\
\hline 3 & 1 & 1 & 1 & 1 & 0 & 1 & 0.5 & 1 & 1 & 1 & 1 & 1 & 1 & 1 & 1 & 1 & 1 & 1 & 0.5 & 0 \\
\hline 4 & 2 & 2 & 0 & 0 & 2 & 2 & 2 & 2 & 2 & 2 & 2 & 2 & 2 & 2 & 2 & 0.5 & 0.5 & 2 & 2 & 2 \\
\hline 5 & 0 & 0 & 4 & 4 & 2 & 1 & 2 & 2 & 2 & 2 & 2 & 2 & 2 & 2 & 3 & 0.5 & 0.5 & 2 & 2 & 2 \\
\hline 7 & 1 & 1 & 0 & 0 & 1 & 1 & 1.5 & 1 & 1.5 & 1 & 1 & 1 & 1 & 1 & 1.5 & 0.5 & 0.5 & 1 & 1 & 1 \\
\hline $\begin{array}{c}\text { flank } \\
\times 6 \neq\end{array}$ & & & 1 & 1 & & & & & -1 & & & & & & -1 & 0.5 & 0.5 & & & \\
\hline
\end{tabular}

Residues at positions $1-5$ and 7 in the core of the motif are allocated scores indicating the extent to which they are suboptimal. Squares in yellow indicate an ideal residue for that position, which scores zero. The score for the acidic tract is derived from the six residues upstream, each of which is scored as indicated ${ }^{\ddagger}$; the total from all six residues (varying between -6 and +6 ) is then converted to a overall score. This set of scores was devised from testing of a limited range of substitutions in motifs and from an analysis of homologues of proteins with FFAT motifs [30], and then updated in the light of subsequent discoveries ${ }^{[10,34]}$. However, much more testing of FFAT-like motifs is needed to improve accuracy. Canonical FFAT motifs score zero; random protein sequences score on average 11.2 (S.D. \pm 1.8 ; maximum $=13.5$ ). The average best FFATlike sequence in 286 control proteins scored 4.6 (S.D. \pm 0.9 ), see Fig. 2A. An editable Microsoft Excel ${ }^{\mathrm{TM}}$ workbook that scans proteins for their four strongest FFAT-like motifs is supplied as Supplementary File 1. Substitution at position 2 (other than Y) is heavily penalized because no unequivocal instance has been reported of a FFAT-like sequence that lacks either $\mathrm{F}^{2}$ or $\mathrm{Y}^{2}$. To reflect this, the workbook highlights any motif detected that might be optimal in many ways, except that it is substituted at position 2 . 
Table 1: Detailed analysis of FFAT-like motifs in the VAPome reported by BioPlex

\section{A. Summary of overlap between VAP interactors in BioPlex and in the original study of FFAT motifs}

\begin{tabular}{|c|c|c|c|c|c|c|}
\hline & as-bai & -tar & total & $\begin{array}{l}\text { integral ER } \\
\text { membrane }\end{array}$ & cytoplasmic & EFFDAxE[14] \\
\hline VAP-A & $56^{\circ}$ & 5 & 60 & 5 & 55 & 11 \\
\hline VAP- & 75 & $4^{\circ}$ & $78^{\circ}$ & 1 & 77 & 12 \\
\hline overal & $\overline{85}$ & 8 & $\overline{92}$ & $\overline{6}$ & $\overline{86}$ & $\overline{12}$ \\
\hline
\end{tabular}

B. Originally defined FFAT motifs $(n=12)$

leaving: 74 not previously studied

\begin{tabular}{|c|l|}
\hline $\begin{array}{l}\text { suboptimal } \\
\text { score }\end{array}$ & Protein name \\
\hline 0 & ${\text { OSBP, ORP4, RdgB } \alpha \mathrm{I}, \mathrm{RdgB} \alpha \mathrm{II}, \mathrm{RdgB} \alpha \mathrm{III}^{\ddagger}}$ \\
\hline 0.5 & Rab3GAP1, Rabphilin-11 \\
\hline 1 & ORP3, ORP6, ORP9a \\
\hline 1.5 & ORP1, ORP2 \\
\hline
\end{tabular}

C. Other VAP interactors $(n=74)$

\begin{tabular}{|c|c|c|}
\hline \multicolumn{2}{|c|}{$\begin{array}{l}\text { suboptimal } \\
\text { score }\end{array}$} & Protein name \\
\hline \multirow{6}{*}{$\begin{array}{l}\text { strong } \\
(n=24)\end{array}$} & 0 & VPS13C* \\
\hline & 0.5 & \\
\hline & 1 & AKAP11*c, LSG1, TACC1*, VPS13A* \\
\hline & 1.5 & LARG* $^{*}$, FAM73B* JMY`[38], TubulinA1C \\
\hline & 2 & AHCTF1, CEBPZ, NACAD, RASSF1 d $¥[98]$, Secernin-1, SNX2 ${ }^{\mathrm{e}}$, SPEG, TTC39B \\
\hline & 2.5 & ACBD5, Aftiphilin, FAM170A, GPN3, MAP4K3, Synergin- $\gamma$, TPR1[36] \\
\hline \multirow{3}{*}{$\begin{array}{c}\text { weak } \\
(n=50)\end{array}$} & 3 & FAM83G, PCTP, PTPIP51•[37], RBCC1, SNX25, USP20`[97], ZDBF2 \\
\hline & 3.5 & $\begin{array}{l}\text { Ankycorbin, BRIP1, CELSR2, DOP1, HEATR5B, } \\
\text { MICAL3, ORP10A, ORP11A, RMD2, STK3ㄹ, STK4, USP33•[97] }\end{array}$ \\
\hline & 4 & CCNB2, NBR1, SLC25A35, SLC6A15, TRIOBP \\
\hline \multirow{5}{*}{$\begin{array}{c}\text { Label }^{\mathrm{A}-\mathrm{E}} \\
\mathrm{x} 10 \rightarrow \text { bind } \\
\text { proteins } \\
\text { above }^{\mathrm{a}-\mathrm{e}}\end{array}$} & 4.5 & $\begin{array}{l}\text { FAM118B, PRKAR1AC, PSTPIP2, Rab3GAP2', SerpinB9, SLC26A2, SLC39A8, } \\
\text { TNFRSF3, ZFPL1 }\end{array}$ \\
\hline & 5 & CTU2, MPRIP, NDUF 2 subunits, NOL11, PKA C- $\beta^{\mathrm{C}}$, PTPN12, SNX5E, SNX6Е \\
\hline & 5.5 & NDUF x2 subunits, PKA C- $\gamma$, PRKAR1BC, SLC39A9, SLC7A2 \\
\hline & 6 & NDUF $x 1$ subunit, \\
\hline & 6.5 & NDUF $x 1$ subunit \\
\hline
\end{tabular}

A. 56,000 human protein interactions from BioPlex ${ }^{[11]}$ were mined for VAP-A and VAP-B entries both as baits and as targets. Integral ER membrane proteins (EIF2AK3, MOSPD2, nesprin 2, TRIC-B and protrudin, the latter having been studied in detail [33]) were excluded. This left 86 non-redundant cytoplasmic interactors, of which 12 had originally defined FFAT motifs ${ }^{[14]}$. ${ }^{\circ}$ includes VAP-A-VAP-B interaction. B and C. The 86 cytoplasmic VAP interactors were scored for the number of sub-optimal elements in their strongest FFAT-like motif using the algorithm in Box 1. B: 12 VAP interactors with originally defined FFAT motifs are shown in order of increasing number of suboptimal elements in the motif. All but one protein* bound both VAP-A and VAP-B. C: 74 human VAP interactors in BioPlex are shown in order of increasing number of suboptimal elements in their strongest FFAT-like motif. The red line indicates the cut-off we use to divide strong $(n=24)$ and weak $(n=50)$ FFAT-like motifs (see Fig. 2A). Motifs from parts $\mathbf{B}$ and $\mathbf{C}$ are shown in detail in Supplementary Fig. 1. Previous findings curated at Genemania.org indicate that 10 VAP interactors with weak motifs (A-E in bottom half of C) may bind VAP indirectly, as they bind proteins in B $\mathrm{a}, \mathrm{b}$ or in the top half of $\mathrm{C}$ c,d,e (see Supplementary Fig. 2). For alternate protein names, see Supplementary Table 1. Notes: •Two strong and three weak interactors have been studied in detail without detection of the motif. *Six interactions were previously predicted [30]. ‡ RASSF1 isoform C only. 
Table 2: Functions of VAP interactors via FFAT or strong FFAT-like motifs

Lipids: PI4P, cholesterol, others: OSBP, ORP1-4 \& 6,9,10*,11* [21, 24,34,91]

PI, PC, PA: RdgB $\alpha I-I I I[71,72,92]$

Fatty acids: ACBD5

PI3P (on ER): SPEG

Membrane traffic: ER morphology: Rab3GAP1 \& 2* [19]

Post-Golgi: Aftiphilin, Secernin-1, Synergin- $\gamma$

Endosomes: Rabphilin-11, SNX2/5*/6*, VPS13A \& C

Cytoskeleton: Microtubules: TACC1, Tubulin- $\alpha 1 \mathrm{C}$

Actin: JMY[38], LARG,

Signaling: cAMP: AKAP11, PRKACB*, PRKAR1A*, PRKAR1B*

other pathways: MAP4K3, NACAD, RASSF1キ, STK3*, STK4*, TPR1[36]

Nuclear: AHCTF1, CEBPZ, FAM170A, GPN3, LSG1

Unknown: FAM73B, TTC39B

Identified Previously:

ER-associated degradation: FAF1 [10]

ER insertion of tail-anchored proteins: ASNA1 [10]

\section{Legend:}

Overall function groupings are listed for 46 VAP interactors identified by BioPlex either that have FFAT motifs, or that have strong FFAT-like motifs as defined in Fig. 3A, or that bind to one of these proteins*. Also function identified by Baron et al. (2014) are shown [10]. ₹ The FFAT in RASSF1c was overlooked previously [30]; this isoform (270 aa) has a strong FFAT-like motif residues 33-39), while in isoform A (340 aa) residues 1-49 are replaced with an alternate 123 residues. References indicate studies that previously showed proteins to be associated with the ER. Alternate names and explanations of acronyms for proteins are given in Supplementary Table 1. 


\section{References}

1. Nishimura, A.L., Mitne-Neto, M., Silva, H.C., Richieri-Costa, A., Middleton, S., Cascio, D., Kok, F., Oliveira, J.R., Gillingwater, T., Webb, J., et al. (2004) A mutation in the vesicle-trafficking protein VAPB causes late-onset spinal muscular atrophy and amyotrophic lateral sclerosis. Am J Hum Genet. 75, 822-31

2. Chen, H.J., Anagnostou, G., Chai, A., Withers, J., Morris, A., Adhikaree, J., Pennetta, G., and de Belleroche, J.S. (2010) Characterization of the properties of a novel mutation in VAPB in familial amyotrophic lateral sclerosis. J Biol Chem. 285, 40266-81

3. Kabashi, E., El Oussini, H., Bercier, V., Gros-Louis, F., Valdmanis, P.N., McDearmid, J., Mejier, I.A., Dion, P.A., Dupre, N., Hollinger, D., et al. (2013) Investigating the contribution of VAPB/ALS8 loss of function in amyotrophic lateral sclerosis. Hum Mol Genet. 22, 2350-60

4. Chattopadhyay, D. and Sengupta, S. (2014) First evidence of pathogenicity of V234I mutation of hVAPB found in Amyotrophic Lateral Sclerosis. Biochem Biophys Res Commun. 448, 108-13

5. Lev, S., Ben Halevy, D., Peretti, D., and Dahan, N. (2008) The VAP protein family: from cellular functions to motor neuron disease. Trends Cell Biol. 18, 282-90

6. Ackerman, S.L. and Cox, G.A. (2008) From ER to Eph receptors: new roles for VAP fragments. Cell. 133, 949-51

7. Ling, S.C., Polymenidou, M., and Cleveland, D.W. (2013) Converging mechanisms in ALS and FTD: disrupted RNA and protein homeostasis. Neuron. 79, 416-38

8. Skehel, P.A., Martin, K.C., Kandel, E.R., and Bartsch, D. (1995) A VAMP-binding protein from Aplysia required for neurotransmitter release. Science. 269, 1580-3

9. Weir, M.L., Xie, H., Klip, A., and Trimble, W.S. (2001) VAP-A binds promiscuously to both vand tSNAREs. Biochem Biophys Res Commun. 286, 616-21

10. Baron, Y., Pedrioli, P.G., Tyagi, K., Johnson, C., Wood, N.T., Fountaine, D., Wightman, M., and Alexandru, G. (2014) VAPB/ALS8 interacts with FFAT-like proteins including the p97 cofactor FAF1 and the ASNA1 ATPase. BMC Biol. 12, 39

11. Huttlin, E.L., Ting, L., Bruckner, R.J., Gebreab, F., Gygi, M.P., Szpyt, J., Tam, S., Zarraga, G., Colby, G., Baltier, K., et al. (2015) The BioPlex Network: A Systematic Exploration of the Human Interactome. Cell. 162, 425-40

12. Rao, M., Song, W., Jiang, A., Shyr, Y., Lev, S., Greenstein, D., Brantley-Sieders, D., and Chen, J. (2012) VAMP-associated protein B (VAPB) promotes breast tumor growth by modulation of Akt activity. PLoS One. 7, e46281

13. Petkovic, M., Jemaiel, A., Daste, F., Specht, C.G., Izeddin, I., Vorkel, D., Verbavatz, J.M., Darzacq, X., Triller, A., Pfenninger, K.H., et al. (2014) The SNARE Sec22b has a nonfusogenic function in plasma membrane expansion. Nat Cell Biol. 16, 434-44

14. Loewen, C.J., Roy, A., and Levine, T.P. (2003) A conserved ER targeting motif in three families of lipid binding proteins and in Opi1p binds VAP. EMBO J. 22, 2025-35

15. Loewen, C.J. and Levine, T.P. (2005) A highly conserved binding site in VAP for the FFAT motif of lipid binding proteins. J Biol Chem. 280, 14097-14104

16. Kaiser, S.E., Brickner, J.H., Reilein, A.R., Fenn, T.D., Walter, P., and Brunger, A.T. (2005) Structural basis of FFAT motif-mediated ER targeting. Structure. 13, 1035-45

17. Furuita, K., Jee, J., Fukada, H., Mishima, M., and Kojima, C. (2010) Electrostatic interaction between oxysterol-binding protein and VAMP-associated protein A revealed by NMR and mutagenesis studies. J Biol Chem. 285, 12961-70

18. Manford, A.G., Stefan, C.J., Yuan, H.L., Macgurn, J.A., and Emr, S.D. (2012) ER-to-plasma membrane tethering proteins regulate cell signaling and ER morphology. Dev Cell. 23, 1129-40

19. Gerondopoulos, A., Bastos, R.N., Yoshimura, S., Anderson, R., Carpanini, S., Aligianis, I., Handley, M.T., and Barr, F.A. (2014) Rab18 and a Rab18 GEF complex are required for normal ER structure. J Cell Biol. 205, 707-20 
20. Loewen, C.J., Gaspar, M.L., Jesch, S.A., Delon, C., Ktistakis, N.T., Henry, S.A., and Levine, T.P. (2004) Phospholipid metabolism regulated by a transcription factor sensing phosphatidic acid. Science. 304, 1644-7

21. Wyles, J.P. and Ridgway, N.D. (2004) VAMP-associated protein-A regulates partitioning of oxysterol-binding protein-related protein- 9 between the endoplasmic reticulum and Golgi apparatus. Exp Cell Res. 297, 533-47

22. Amarilio, R., Ramachandran, S., Sabanay, H., and Lev, S. (2004) Differential regulation of ER structure through VAP-Nir protein interaction. J Biol Chem. 280, 5933-5944

23. Kawano, M., Kumagai, K., Nishijima, M., and Hanada, K. (2006) Efficient trafficking of ceramide from the endoplasmic reticulum to the Golgi apparatus requires a VAMPassociated protein-interacting FFAT motif of CERT. J Biol Chem. 281, 30279-88

24. Wyles, J.P., McMaster, C.R., and Ridgway, N.D. (2002) Vesicle-associated membrane protein-associated protein-A (VAP-A) interacts with the oxysterol-binding protein to modify export from the endoplasmic reticulum. J Biol Chem. 277, 29908-18

25. Levine, T. (2004) Short-range intracellular trafficking of small molecules across endoplasmic reticulum junctions. Trends Cell Biol. 14, 483-90

26. Bernhard, W. and Rouiller, C. (1956) Close topographical relationship between mitochondria and ergastoplasm of liver cells in a definite phase of cellular activity. J Biophys Biochem Cytol. 2, 73-8

27. Holthuis, J.C. and Menon, A.K. (2014) Lipid landscapes and pipelines in membrane homeostasis. Nature. 510, 48-57

28. Prinz, W.A. (2014) Bridging the gap: membrane contact sites in signaling, metabolism, and organelle dynamics. J Cell Biol. 205, 759-69

29. Ungermann, C. (2015) vCLAMPs - an intimate link between vacuoles and mitochondria. Current Opinion in Cell Biology. 35, 30-36

30. Mikitova, V. and Levine, T.P. (2012) Analysis of the key elements of FFAT-like motifs identifies new proteins that potentially bind VAP on the ER, including two AKAPs and FAPP2. PLoS One. 7, e30455

31. Alpy, F., Rousseau, A., Schwab, Y., Legueux, F., Stoll, I., Wendling, C., Spiegelhalter, C., Kessler, P., Mathelin, C., Rio, M.C., et al. (2013) STARD3 or STARD3NL and VAP form a novel molecular tether between late endosomes and the ER. J Cell Sci. 126, 5500-12

32. Riekhof, W.R., Wu, W.I., Jones, J.L., Nikrad, M., Chan, M.M., Loewen, C.J., and Voelker, D.R. (2014) An assembly of proteins and lipid domains regulates transport of phosphatidylserine to phosphatidylserine decarboxylase 2 in Saccharomyces cerevisiae. J Biol Chem. 289, 5809-19

33. Saita, S., Shirane, M., Natume, T., Iemura, S., and Nakayama, K.I. (2009) Promotion of neurite extension by protrudin requires its interaction with vesicle-associated membrane protein-associated protein. J Biol Chem. 284, 13766-77

34. Weber-Boyvat, M., Kentala, H., Lilja, J., Vihervaara, T., Hanninen, R., Zhou, Y., Peranen, J., Nyman, T.A., Ivaska, J., and Olkkonen, V.M. (2015) OSBP-related protein 3 (ORP3) coupling with VAMP-associated protein A regulates R-Ras activity. Exp Cell Res. 331, 278-91

35. Gattiker, A., Gasteiger, E., and Bairoch, A. (2002) ScanProsite: a reference implementation of a PROSITE scanning tool. Appl Bioinformatics. 1, 107-8

36. Lotz, G.P., Brychzy, A., Heinz, S., and Obermann, W.M. (2008) A novel HSP90 chaperone complex regulates intracellular vesicle transport. J Cell Sci. 121, 717-23

37. De Vos, K.J., Morotz, G.M., Stoica, R., Tudor, E.L., Lau, K.F., Ackerley, S., Warley, A., Shaw, C.E., and Miller, C.C. (2011) VAPB interacts with the mitochondrial protein PTPIP51 to regulate calcium homeostasis. Hum Mol Genet.

38. Schluter, K., Waschbusch, D., Anft, M., Hugging, D., Kind, S., Hanisch, J., Lakisic, G., Gautreau, A., Barnekow, A., and Stradal, T.E. (2014) JMY is involved in anterograde vesicle trafficking from the trans-Golgi network. Eur J Cell Biol. 93, 194-204 
39. Wang, P., Hawkins, T.J., Richardson, C., Cummins, I., Deeks, M.J., Sparkes, I., Hawes, C., and Hussey, P.J. (2014) The plant cytoskeleton, NET3C, and VAP27 mediate the link between the plasma membrane and endoplasmic reticulum. Curr Biol. 24, 1397-405

40. Tuuf, J., Wistbacka, L., and Mattjus, P. (2009) The glycolipid transfer protein interacts with the vesicle-associated membrane protein-associated protein VAP-A. Biochem Biophys Res Commun. 388, 395-9

41. Gavin, A.C., Bosche, M., Krause, R., Grandi, P., Marzioch, M., Bauer, A., Schultz, J., Rick, J.M., Michon, A.M., Cruciat, C.M., et al. (2002) Functional organization of the yeast proteome by systematic analysis of protein complexes. Nature. 415, 141-7

42. Ho, Y., Gruhler, A., Heilbut, A., Bader, G.D., Moore, L., Adams, S.L., Millar, A., Taylor, P., Bennett, K., Boutilier, K., et al. (2002) Systematic identification of protein complexes in Saccharomyces cerevisiae by mass spectrometry. Nature. 415, 180-3

43. Ernst, W.L., Shome, K., Wu, C.C., Gong, X., Frizzell, R.A., and Aridor, M. (2016) VAP (VAMPAssociated Proteins) as Receptors that couple Cystic Fibrosis Transmembrane Conductance Regulator (CFTR) Proteostasis with Lipid Homeostasis. J Biol Chem.

44. Skehel, P.A., Fabian-Fine, R., and Kandel, E.R. (2000) Mouse VAP33 is associated with the endoplasmic reticulum and microtubules. Proc Natl Acad Sci U S A. 97, 1101-6

45. Mellacheruvu, D., Wright, Z., Couzens, A.L., Lambert, J.P., St-Denis, N.A., Li, T., Miteva, Y.V., Hauri, S., Sardiu, M.E., Low, T.Y., et al. (2013) The CRAPome: a contaminant repository for affinity purification-mass spectrometry data. Nat Methods. 10, 730-6

46. Allison, R., Lumb, J.H., Fassier, C., Connell, J.W., Ten Martin, D., Seaman, M.N., Hazan, J., and Reid, E. (2013) An ESCRT-spastin interaction promotes fission of recycling tubules from the endosome. J Cell Biol. 202, 527-43

47. Chao, J.T., Wong, A.K., Tavassoli, S., Young, B.P., Chruscicki, A., Fang, N.N., Howe, L.J., Mayor, T., Foster, L.J., and Loewen, C.J. (2014) Polarization of the endoplasmic reticulum by ER-septin tethering. Cell. 158, 620-32

48. Neller, J., Dunkler, A., Rosler, R., and Johnsson, N. (2015) A protein complex containing Epo1p anchors the cortical endoplasmic reticulum to the yeast bud tip. J Cell Biol. 208, 7187

49. Westermann, B. (2015) The mitochondria-plasma membrane contact site. Curr Opin Cell Biol. 35, 1-6

50. Loewen, C.J., Young, B.P., Tavassoli, S., and Levine, T.P. (2007) Inheritance of cortical ER in yeast is required for normal septin organization. J Cell Biol. 179, 467-83

51. Gupta, G., Qin, H., and Song, J. (2012) Intrinsically unstructured domain 3 of hepatitis C Virus NS5A forms a "fuzzy complex" with VAPB-MSP domain which carries ALS-causing mutations. PLoS One. 7, e39261

52. Gupta, G. and Song, J. (2016) C-Terminal Auto-Regulatory Motif of Hepatitis C Virus NS5B Interacts with Human VAPB-MSP to Form a Dynamic Replication Complex. PLoS One. 11, $\mathrm{e} 0147278$

53. Kim, S., Leal, S.S., Ben Halevy, D., Gomes, C.M., and Lev, S. (2010) Structural requirements for VAP-B oligomerization and their implication in amyotrophic lateral sclerosis-associated VAP-B(P56S) neurotoxicity. J Biol Chem. 285, 13839-49

54. Wilson, J.D., Thompson, S.L., and Barlowe, C. (2011) Yet1p-Yet3p interacts with Scs2pOpi1p to regulate ER localization of the Opi1p repressor. Mol Biol Cell. 22, 1430-9

55. Annaert, W.G., Becker, B., Kistner, U., Reth, M., and Jahn, R. (1997) Export of cellubrevin from the endoplasmic reticulum is controlled by BAP31. J Cell Biol. 139, 1397-410

56. Simmen, T., Aslan, J.E., Blagoveshchenskaya, A.D., Thomas, L., Wan, L., Xiang, Y., Feliciangeli, S.F., Hung, C.H., Crump, C.M., and Thomas, G. (2005) PACS-2 controls endoplasmic reticulum-mitochondria communication and Bid-mediated apoptosis. Embo J. $24,717-29$ 
57. Gkogkas, C., Middleton, S., Kremer, A.M., Wardrope, C., Hannah, M., Gillingwater, T.H., and Skehel, P. (2008) VAPB interacts with and modulates the activity of ATF6. Hum Mol Genet. $17,1517-26$

58. Kuijpers, M., van Dis, V., Haasdijk, E.D., Harterink, M., Vocking, K., Post, J.A., Scheper, W., Hoogenraad, C.C., and Jaarsma, D. (2013) Amyotrophic lateral sclerosis (ALS)-associated VAPB-P56S inclusions represent an ER quality control compartment. Acta Neuropathol Commun. 1, 24

59. Forrest, S., Chai, A., Sanhueza, M., Marescotti, M., Parry, K., Georgiev, A., Sahota, V., Mendez-Castro, R., and Pennetta, G. (2013) Increased levels of phosphoinositides cause neurodegeneration in a Drosophila model of amyotrophic lateral sclerosis. Hum Mol Genet. 22, 2689-704

60. Stefan, C.J., Manford, A.G., Baird, D., Yamada-Hanff, J., Mao, Y., and Emr, S.D. (2011) Osh proteins regulate phosphoinositide metabolism at ER-plasma membrane contact sites. Cell. $144,389-401$

61. Olkkonen, V.M. (2015) OSBP-Related Protein Family in Lipid Transport Over Membrane Contact Sites. Lipid Insights. 8, 1-9

62. Wakana, Y., Kotake, R., Oyama, N., Murate, M., Kobayashi, T., Arasakia, K., Inouea, H., and Tagaya, M. (2015) CARTS biogenesis requires VAP-lipid transfer protein complexes functioning at the endoplasmic reticulum-Golgi interface. Mol Biol Cell. 26, epub; mbc.E1508-0599

63. Kagiwada, S. and Hashimoto, M. (2007) The yeast VAP homolog Scs2p has a phosphoinositide-binding ability that is correlated with its activity. Biochem Biophys Res Commun. 364, 870-6

64. Stoica, R., De Vos, K.J., Paillusson, S., Mueller, S., Sancho, R.M., Lau, K.F., Vizcay-Barrena, G., Lin, W.L., Xu, Y.F., Lewis, J., et al. (2014) ER-mitochondria associations are regulated by the VAPB-PTPIP51 interaction and are disrupted by ALS/FTD-associated TDP-43. Nat Commun. 5, 3996

65. Kumagai, K., Kawano-Kawada, M., and Hanada, K. (2014) Phosphoregulation of the ceramide transport protein CERT at serine 315 in the interaction with VAMP-associated protein (VAP) for inter-organelle trafficking of ceramide in mammalian cells. J Biol Chem. $289,10748-60$

66. Kuijpers, M., Yu, K.L., Teuling, E., Akhmanova, A., Jaarsma, D., and Hoogenraad, C.C. (2013) The ALS8 protein VAPB interacts with the ER-Golgi recycling protein YIF1A and regulates membrane delivery into dendrites. Embo J. 32, 2056-72

67. Soussan, L., Burakov, D., Daniels, M.P., Toister-Achituv, M., Porat, A., Yarden, Y., and Elazar, Z. (1999) ERG30, a VAP-33-related protein, functions in protein transport mediated by COPI vesicles. J Cell Biol. 146, 301-11

68. Fasana, E., Fossati, M., Ruggiano, A., Brambillasca, S., Hoogenraad, C.C., Navone, F., Francolini, M., and Borgese, N. (2010) A VAPB mutant linked to amyotrophic lateral sclerosis generates a novel form of organized smooth endoplasmic reticulum. Faseb J. 24, 1419-30

69. De Matteis, M.A. and Rega, L.R. (2015) Endoplasmic reticulum-Golgi complex membrane contact sites. Curr Opin Cell Biol. 35, 43-50

70. Mesmin, B., Bigay, J., Moser von Filseck, J., Lacas-Gervais, S., Drin, G., and Antonny, B. (2013) A four-step cycle driven by PI(4)P hydrolysis directs sterol/PI(4)P exchange by the ER-Golgi tether OSBP. Cell. 155, 830-43

71. Kim, Y.J., Guzman-Hernandez, M.L., Wisniewski, E., and Balla, T. (2015) Phosphatidylinositol-Phosphatidic Acid Exchange by Nir2 at ER-PM Contact Sites Maintains Phosphoinositide Signaling Competence. Dev Cell. 33, 549-61

72. Yadav, S., Garner, K., Georgiev, P., Li, M., Gomez-Espinosa, E., Panda, A., Mathre, S., Okkenhaug, H., Cockcroft, S., and Raghu, P. (2015) RDGBalpha, a PI-PA transfer protein 
regulates G-protein coupled PtdIns(4,5)P2 signalling during Drosophila phototransduction. J Cell Sci. epub, jcs.173476

73. Barajas, D., Xu, K., de Castro Martin, I.F., Sasvari, Z., Brandizzi, F., Risco, C., and Nagy, P.D. (2014) Co-opted oxysterol-binding ORP and VAP proteins channel sterols to RNA virus replication sites via membrane contact sites. PLoS Pathog. 10, e1004388

74. Roulin, P.S., Lotzerich, M., Torta, F., Tanner, L.B., van Kuppeveld, F.J., Wenk, M.R., and Greber, U.F. (2014) Rhinovirus uses a phosphatidylinositol 4-phosphate/cholesterol counter-current for the formation of replication compartments at the ER-Golgi interface. Cell Host Microbe. 16, 677-90

75. Derre, I. (2015) Chlamydiae interaction with the endoplasmic reticulum: contact, function and consequences. Cell Microbiol. 17, 959-66

76. Burgoyne, T., Patel, S., and Eden, E.R. (2015) Calcium signaling at ER membrane contact sites. Biochim Biophys Acta. 1853, 2012-7

77. Jing, J., He, L., Sun, A., Quintana, A., Ding, Y., Ma, G., Tan, P., Liang, X., Zheng, X., Chen, L., et al. (2015) Proteomic mapping of ER-PM junctions identifies STIMATE as a regulator of $\mathrm{Ca}(2)(+)$ influx. Nat Cell Biol. 17, 1339-47

78. Anagnostou, G., Akbar, M.T., Paul, P., Angelinetta, C., Steiner, T.J., and de Belleroche, J. (2010) Vesicle associated membrane protein B (VAPB) is decreased in ALS spinal cord. Neurobiol Aging. 31, 969-85

79. Kun-Rodrigues, C., Ganos, C., Guerreiro, R., Schneider, S.A., Schulte, C., Lesage, S., Darwent, L., Holmans, P., Singleton, A., Bhatia, K., et al. (2015) A systematic screening to identify de novo mutations causing sporadic early-onset Parkinson's disease. Hum Mol Genet.

80. Papiani, G., Ruggiano, A., Fossati, M., Raimondi, A., Bertoni, G., Francolini, M., Benfante, R., Navone, F., and Borgese, N. (2012) Restructured endoplasmic reticulum generated by mutant amyotrophic lateral sclerosis-linked VAPB is cleared by the proteasome. J Cell Sci. $125,3601-11$

81. Larroquette, F., Seto, L., Gaub, P.L., Kamal, B., Wallis, D., Lariviere, R., Vallee, J., Robitaille, R., and Tsuda, H. (2015) Vapb/Amyotrophic lateral sclerosis 8 knock-in mice display slowly progressive motor behavior defects accompanying ER stress and autophagic response. Hum Mol Genet. 24, 6515-29

82. Ratnaparkhi, A., Lawless, G.M., Schweizer, F.E., Golshani, P., and Jackson, G.R. (2008) A Drosophila model of ALS: human ALS-associated mutation in VAP33A suggests a dominant negative mechanism. PLoS One. 3, e2334

83. Mitne-Neto, M., Machado-Costa, M., Marchetto, M.C., Bengtson, M.H., Joazeiro, C.A., Tsuda, H., Bellen, H.J., Silva, H.C., Oliveira, A.S., Lazar, M., et al. (2011) Downregulation of VAPB expression in motor neurons derived from induced pluripotent stem cells of ALS8 patients. Hum Mol Genet. 20, 3642-52

84. Prosser, D.C., Tran, D., Gougeon, P.Y., Verly, C., and Ngsee, J.K. (2008) FFAT rescues VAPAmediated inhibition of ER-to-Golgi transport and VAPB-mediated ER aggregation. J Cell Sci. $121,3052-61$

85. Moumen, A., Virard, I., and Raoul, C. (2011) Accumulation of wildtype and ALS-linked mutated VAPB impairs activity of the proteasome. PLoS One. 6, e26066

86. Raiborg, C., Wenzel, E.M., Pedersen, N.M., Olsvik, H., Schink, K.O., Schultz, S.W., Vietri, M., Nisi, V., Bucci, C., Brech, A., et al. (2015) Repeated ER-endosome contacts promote endosome translocation and neurite outgrowth. Nature. 520, 234-8

87. Moustaqim-Barrette, A., Lin, Y.Q., Pradhan, S., Neely, G.G., Bellen, H.J., and Tsuda, H. (2014) The amyotrophic lateral sclerosis 8 protein, VAP, is required for ER protein quality control. Hum Mol Genet. 23, 1975-89

88. Kanekura, K., Nishimoto, I., Aiso, S., and Matsuoka, M. (2006) Characterization of amyotrophic lateral sclerosis-linked P56S mutation of vesicle-associated membrane protein-associated protein B (VAPB/ALS8). J Biol Chem. 281, 30223-33 
89. Beene, D.L. and Scott, J.D. (2007) A-kinase anchoring proteins take shape. Curr Opin Cell Biol. 19, 192-8

90. Teuling, E., Ahmed, S., Haasdijk, E., Demmers, J., Steinmetz, M.O., Akhmanova, A., Jaarsma, D., and Hoogenraad, C.C. (2007) Motor neuron disease-associated mutant vesicleassociated membrane protein-associated protein (VAP) B recruits wild-type VAPs into endoplasmic reticulum-derived tubular aggregates. J Neurosci. 27, 9801-15

91. Goto, A., Liu, X., Robinson, C.A., and Ridgway, N.D. (2012) Multisite phosphorylation of oxysterol-binding protein regulates sterol binding and activation of sphingomyelin synthesis. Mol Biol Cell. 23, 3624-35

92. Peretti, D., Dahan, N., Shimoni, E., Hirschberg, K., and Lev, S. (2008) Coordinated lipid transfer between the endoplasmic reticulum and the Golgi complex requires the VAP proteins and is essential for Golgi-mediated transport. Mol Biol Cell. 19, 3871-84

93. Rocha, N., Kuijl, C., van der Kant, R., Janssen, L., Houben, D., Janssen, H., Zwart, W., and Neefjes, J. (2009) Cholesterol sensor ORP1L contacts the ER protein VAP to control Rab7RILP-p150 Glued and late endosome positioning. J Cell Biol. 185, 1209-25

94. Jansen, M., Ohsaki, Y., Rita Rega, L., Bittman, R., Olkkonen, V.M., and Ikonen, E. (2011) Role of ORPs in sterol transport from plasma membrane to ER and lipid droplets in mammalian cells. Traffic. 12, 218-31

95. Means, C.K., Lygren, B., Langeberg, L.K., Jain, A., Dixon, R.E., Vega, A.L., Gold, M.G., Petrosyan, S., Taylor, S.S., Murphy, A.N., et al. (2011) An entirely specific type I A-kinase anchoring protein that can sequester two molecules of protein kinase A at mitochondria. Proc Natl Acad Sci U S A. 108, E1227-35

96. Whiting, J.L., Nygren, P.J., Tunquist, B.J., Langeberg, L.K., Seternes, O.M., and Scott, J.D. (2015) Protein Kinase A Opposes the Phosphorylation-dependent Recruitment of Glycogen Synthase Kinase 3beta to A-kinase Anchoring Protein 220. J Biol Chem. 290, 19445-57

97. Thorne, C., Eccles, R.L., Coulson, J.M., Urbe, S., and Clague, M.J. (2011) Isoform-specific localization of the deubiquitinase USP33 to the Golgi apparatus. Traffic. 12, 1563-74

98. Hutchins, J.R., Toyoda, Y., Hegemann, B., Poser, I., Heriche, J.K., Sykora, M.M., Augsburg, M., Hudecz, O., Buschhorn, B.A., Bulkescher, J., et al. (2010) Systematic analysis of human protein complexes identifies chromosome segregation proteins. Science. 328, 593-9 


\section{Figure 1}

A

major sperm protein domain

transmembrane helix

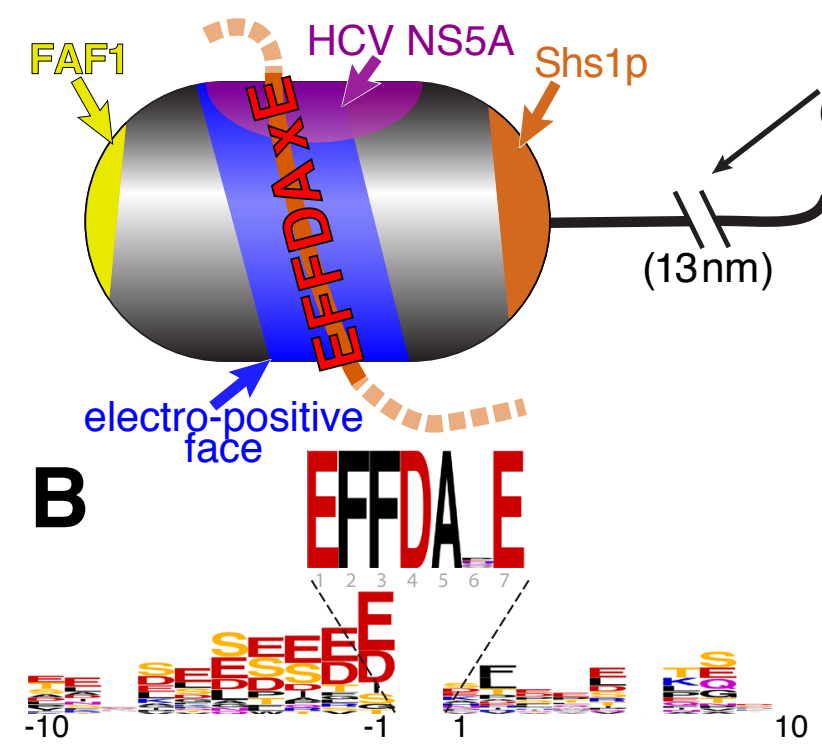

$\begin{array}{llc}\text { D } & \text { EFFDA E E } & \begin{array}{c}\text { suboptimal } \\ \text { elements }\end{array} \\ \text { OSBP } & \text { THIYRGEYWECKE } & 2.0 \\ \text { Osh1p } & \text { NKRKNHDFKDCAD } & 2.5 \\ & \text { SIETVSEFFDKLN } & 4 \\ \text { CERT } & \text { VEDDEDDFPTRS } & 2.5 \\ & \text { QVDTLKYFDACA } & 4 \\ \text { RabGAP1 } & \text { EVFEITDFTTASE } & 2.5 \\ \text { Orp2 } & \text { SDNSSGEFSEANQ } & 3 \\ \text { Nir2 } & \text { FFDAHEGFSDSEE } & 3.5 \\ \text { Orp3 } & \text { DFGEEKNYSDGSE } & 4 \\ & \text { FPHEVNHFFGST* } & 4.5 \\ \text { Opi1p } & \text { YDYNDDEFFTNKR } & 4\end{array}$

\begin{tabular}{|c|c|c|}
\hline \multicolumn{3}{|c|}{ EFFDA E $\begin{array}{c}\text { suboptimal } \\
\text { elements }\end{array}$} \\
\hline FAF1 & $\begin{array}{l}\text { SDSDGDDFEDATE* } \\
\text { LFPQETLFLEAKE }\end{array}$ & 3.5 \\
\hline Protrudin & EAEPDEEFKDAIE* & 1 \\
\hline JMY & ETDDPEEYYESLS & 1.5 \\
\hline ASNA1 & WGVEAEEFEDAPD* & 2 \\
\hline TPR1/TTC1 & DQGEEECFHDCSA & 2.7 \\
\hline PTPIP51 & $\begin{array}{l}\text { STGSSSVYFTASS } \\
\text { TASSGATFTDAES }\end{array}$ & $\begin{array}{c}3 \\
3.5\end{array}$ \\
\hline GLTP & $\begin{array}{l}\text { AVSHLPPFFDCLG* } \\
\text { KQIETGPFLEAVS }\end{array}$ & 3.5 \\
\hline NET3C $\ddagger$ & VCDSNSHFEDADS & 3.5 \\
\hline StARD3 & GALSEGQFYSPPE* & 5.5 \\
\hline
\end{tabular}


Figure 2

A

FFAT and FFAT-like motifs

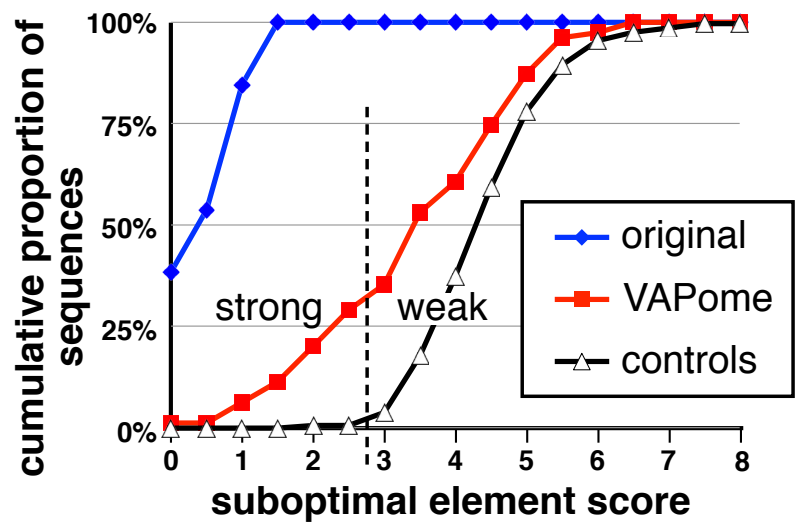

B

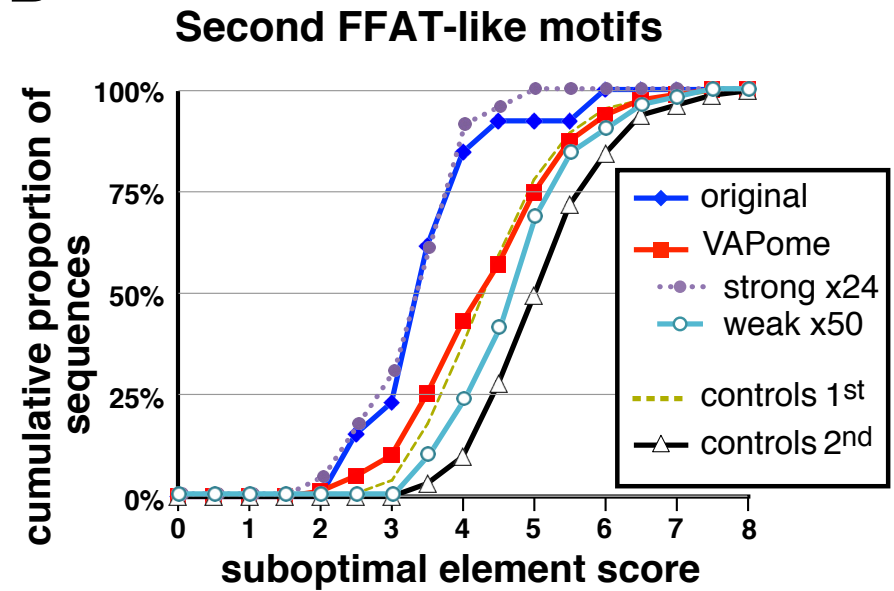




\section{Figure 3}

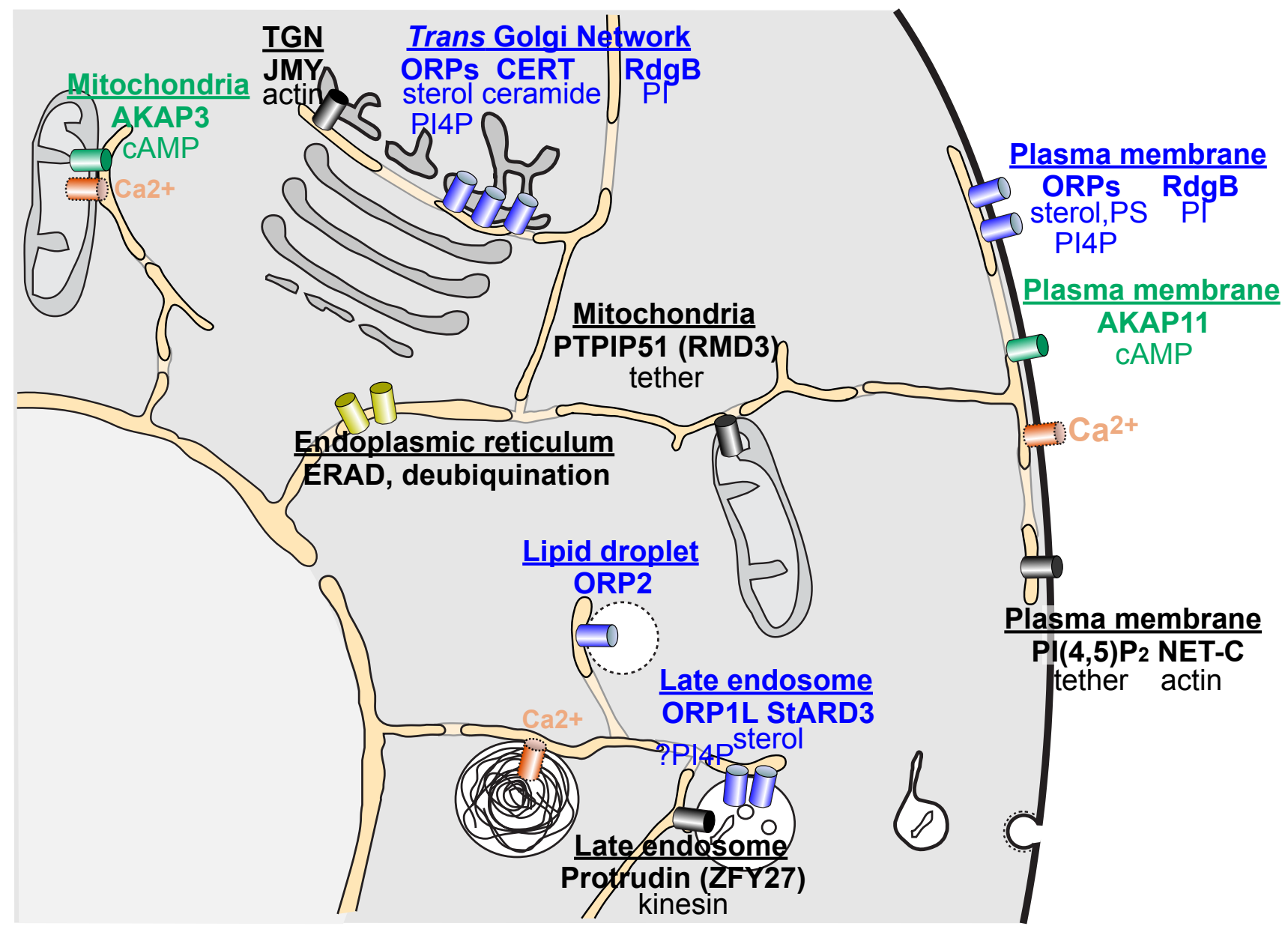




\section{Supplementary Table 1: Description of 74 novel VAP interactors in BioPlex}

\begin{tabular}{|c|c|c|c|c|}
\hline$\underline{\text { Protein }}$ & Alternative gene names & Uniprot & Full name & Function \\
\hline ACBD4 & & ACBD4 & Acyl-CoA-binding domain-containing protein 4 & Lipid \\
\hline ACBD5 & KIAA1996 & ACBD5 & Acyl-CoA-binding domain-containing protein 5 & Lipid \\
\hline AFTPH & AFTH & AFTIN & Aftiphilin & Membrane traffic \\
\hline AHCTF1 & ELYS, TMBS62 & ELYS & Protein ELYS & Nuclear \\
\hline AKAP11 & AKAP220, KIAA0629 & AKA11 & A-kinase anchor protein 11 & Signalling \\
\hline Ankycorbin & KIAA1334, NORPEG & RAI14 & Ankycorbin & Cytoskeleton \\
\hline BRIP1 & BACH1, FANCJ & FANCJ & Fanconi anemia gp J pr, BRCA1-interacting pr & Nuclear \\
\hline CCNB2 & & CCNB2 & G2/mitotic-specific cyclin-B2 & Signalling \\
\hline CEBPZ & CBF2 & CEBPZ & CCAAT/enhancer-binding protein zeta & Nuclear \\
\hline CELSR2 & CDHF10, EGFL2, MEGF3 & CELR2 & Cadherin EGF LAG 7-pass G-type receptor 2 & Signalling \\
\hline CTU2 & C16orf84, NCS2 & CTU2 & Cytoplasmic tRNA 2-thiolation protein 2 & Signalling \\
\hline DOPEY1 & KIAA1117 & DOP1 & Dopey-1 & Membrane traffic \\
\hline FAM118B & & F118B & Protein FAM118B & Nuclear \\
\hline FAM170A & ZNFD & F170A & Protein FAM170A & Nuclear \\
\hline FAM73B & C9orf54 & FA73B & Protein FAM73B & Unknown \\
\hline FAM83G & PAWS1 & FA83G & Protein FAM83G & Signalling \\
\hline GPN3 & ATPBD1C & GPN3 & GPN-loop GTPase 3 & Nuclear \\
\hline HEATR5B & KIAA1414 & HTR5B & HEAT repeat-containing protein 5B & Unknown \\
\hline JMY & & IMY & Junction-mediating and -regulatory protein & Cytoskeleton \\
\hline LARG & ARHGEF12, KIAA0382 & ARHGC & Rho guanine nucleotide exchange factor 12 & Cytoskeleton \\
\hline LSG1 & & LSG1 & Large subunit GTPase 1 homolog & Nuclear \\
\hline MAP4K3 & RAB8IPL1 & M4K3 & MAP kinase kinase kinase kinase 3 & Signalling \\
\hline MICAL3 & KIAA0819, KIAA1364 & MICA3 & Protein-methionine sulfoxide oxidase MICAL3 & Membrane traffic \\
\hline MPRIP & KIAA0864, MRIP, RHOIP3 & MPRIP & Myosin phosphatase Rho-interacting protein & Cytoskeleton \\
\hline NACAD & KIAA0363 & NACAD & NAC-alpha domain-containing protein 1 & Membrane traffic \\
\hline NBR1 & 1A13B, KIAA0049, M17S2 & NBR1 & Next to BRCA1 gene 1 protein & Signalling \\
\hline NDUFA12 & DAP13 & NDUAC & & intra-mitochondrial \\
\hline NDUFA7 & & NDUA7 & \}$\quad$ subunits of & \} intra-mitochondrial \\
\hline NDUFB3 & & NDUB3 & NADH dehydrogenase [ubiquinone] 1 & intra-mitochondrial \\
\hline NDUFB8 & & NDUB8 & i.e. complex I in the mitochondrial & intra-mitochondrial \\
\hline NDUFS4 & & NDUS4 & electron transport chain & \} intra-mitochondrial \\
\hline NDUFS6 & & NDUS6 & & \} intra-mitochondrial \\
\hline NOL11 & & NOL11 & Nucleolar protein 11 & Nuclear \\
\hline PCTP & STARD2 & PPCT & Phosphatidylcholine transfer protein & Lipid \\
\hline PRKACB & PKA C- $\beta$ & КАРСВ & & \} \\
\hline PRKACG & PKA C $-\gamma$ & KAPCG & cAMP-dependent protein kinase type I- & \\
\hline PRKAR1A & PKR1, PRKAR1, TSE1 & KAP0 & regulatory subunits & Signalling \\
\hline PRKAR1B & PRKX, PKX & KAP1 & 0 & \\
\hline PSTPIP2 & & PPIP2 & Pro-ser-thr phosphatase-interacting pr-2 & Cytoskeleton \\
\hline PTPIP51 & FAM82A2, FAM82C, RMDN3 & RMD3 & Regulator of microtubule dynamics pr-3 & Signalling \\
\hline PTPN12 & & PTN12 & Tyrosine-pr phosphatase non-receptor type 12 & Signalling \\
\hline RASSF1 & RDA32 & RASF1 & Ras association domain-containing pr 1 & Nuclear \\
\hline RB1CC1 & KIAA0203, RBICC & RBCC1 & RB1-inducible coiled-coil protein 1 & Signalling \\
\hline RMDN2 & FAM82A1 (see PTPIP51) & RMD2 & Regulator of microtubule dynamics $\mathrm{pr}-2$ & Signalling \\
\hline Secernin-1 & KIAA0193 & SCRN1 & Secernin-1 & Membrane traffic \\
\hline SerpinB9 & PI9 & SPB9 & Serpin B9 & Signalling \\
\hline SLC25A35 & & S2535 & Solute carrier family 25 member 35 & Membrane traffic \\
\hline SLC26A2 & DTD, DTDST & S26A2 & Sulfate transporter & Membrane traffic \\
\hline SLC39A8 & BIGM103, ZIP8 & S39A8 & Zinc transporter ZIP8 & Membrane traffic \\
\hline SLC39A9 & ZIP9 & S39A9 & Zinc transporter ZIP9 & Membrane traffic \\
\hline SLC6A15 & & S6A15 & $\mathrm{Na}+$-dependent neutral aa transporter $\mathrm{B}(0) \mathrm{AT} 2$ & Membrane traffic \\
\hline SLC7A2 & ATRC2, CAT2 & CTR2 & Cationic amino acid transporter 2 & Membrane traffic \\
\hline SNX2 & & SNX2 & Sorting nexin-2 & Lipid \\
\hline SNX25 & & SNX25 & Sorting nexin-25 & Membrane traffic \\
\hline SNX5 & & SNX5 & Sorting nexin-5 & Membrane traffic \\
\hline SNX6 & & SNX6 & Sorting nexin-6 & Membrane traffic \\
\hline SPEG & APEG1, KIAA1297 & SPEG & Striated muscle preferentially expressed kinase & Lipid \\
\hline STK3 & KRS1, MST2 & STK3 & Serine/threonine-protein kinase 3 & Signalling \\
\hline STK4 & KRS2, MST1 & STK4 & Serine/threonine-protein kinase 4 & Signalling \\
\hline Synergin- $\gamma$ & AP1GBP1, SYNG & SYNRG & Synergin gamma & Membrane traffic \\
\hline TACC1 & KIAA1103 & TACC1 & Transforming acidic coiled-coil-containing pr1 & Nuclear \\
\hline TNFRSF3 & LTBR, TNFCR, & TNR3 & TNF receptor superfamily member 3 & Signalling \\
\hline TPR1 & TTC1 & TTC1 & Tetratricopeptide repeat protein 1 & Protein folding \\
\hline TRIOBP & KIAA1662, TARA & TARA & TRIO and F-actin-binding protein & Cytoskeleton \\
\hline TTC39B & C9orf52 & TT39B & Tetratricopeptide repeat protein 39B & Signalling \\
\hline Tubulin $\alpha 1 \mathrm{C}$ & TUBA6 & TBA1C & Tubulin alpha-1C chain & Cytoskeleton \\
\hline USP20 & KIAA1003, LSFR3A, VDU2 & UBP20 & Ubiquitin carboxyl-terminal hydrolase 20 & Signalling \\
\hline USP33 & KIAA1097, VDU1 & UBP33 & Ubiquitin carboxyl-terminal hydrolase 33 & Signalling \\
\hline VPS13A & CHAC, KIAA0986 & VP13A & Vacuolar protein sorting-associated pr 13A & Membrane traffic \\
\hline VPS13C & KIAA1421 & VP13C & Vacuolar protein sorting-associated pr $13 \mathrm{C}$ & Membrane traffic \\
\hline ZDBF2 & KIAA1571 & ZDBF2 & DBF4-type zinc finger-containing protein 2 & Unknown \\
\hline ZFPL1 & & ZFPL1 & Zinc finger protein-like 1 & Membrane traffic \\
\hline
\end{tabular}

Excludes 12 proteins with originally defined FFAT-motifs, and 6 that are integral ER membrane proteins. 


\begin{tabular}{|c|c|c|c|c|c|c|c|c|c|c|}
\hline & $\frac{\text { name }}{\text { A. } 12 \text { known }}$ & $\frac{\text { FF1 }}{\text { otifs }}$ & SEQ1 & FF2 & SEQ2 & continued & FF1 & SEQ1 & FF2 & SEQ2 \\
\hline$\infty$ & OSBP & 0.0 & DEDDENEFFDA & 2.2 & THIYRGEYWEC & РСТР & 3.2 & GSFSEEQFWEA & 5 & PTLLADIYMD \\
\hline & ORP4 & 0.0 & EEDEDTEYFDA & 3.2 & ACVYKGGYWEAI & CELR2 & 3.5 & DVVSPLDYETT & 3.5 & EDDQSGSYASTH \\
\hline 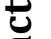 & PITM1 & 0.0 & ENSSEEEFFDAF & 3.2 & PHLFHASYWESZ & FANCJ & 3.5 & KKLKACPYYTA & 3.5 & QIQHHSTFESAL \\
\hline อ & PITM2 & 0.0 & DESSDDEFFDAF & 3.2 & PHLFHASYWES & MICA3 & 3.5 & REEVRKSFVES & 3.5 & ADDVEDTYDDK \\
\hline دِ & PITM3 & 0.0 & VESSDDEFFDAR & 3.2 & PHLFHASYWEST & DOP1 & 3.5 & PEEHATYYFTTF & 4 & KQKTSKEYLSAFI \\
\hline$\Xi$ & Rab3GAP1 & 0.5 & WSDSEEEFFECL & 2.5 & EVFEITDFTTAS & HTR5B & 3.5 & YLLDENSFASAS & 4.5 & EMDDDTMFTTLGF \\
\hline a & Rabphilin11 & 0.5 & SESDTEEFYDAP & 4 & CCFQH IDFVTAIA & ORP11 & 3.5 & HPPVSGFYAECT & 4.5 & SEVASSVFSSSST \\
\hline 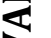 & ORP9 & 1.0 & YSSSEDEFYDAD & 3.5 & YNAGLLSYYTSKD & USP33 & 3.5 & KSQSDVDFQSCES & 4.5 & CPPLTQFFLDCGG \\
\hline & ORP3 & 1.0 & ITDSLSEFFDA & 4 & DFGEEKNYSDGS & STK3 & 3.5 & QRP SFMDYF DKQ & 5 & DLWIVMEYCGAGS \\
\hline & ORP6 & 1.0 & MSESVSEFFDAC & 4 & HLCEEMEYSELI & STK4 & 3.5 & ÄKPSFLEYFEQF & 5 & DLWIVMEYCGAGS \\
\hline & ORP2 & 1.5 & XMNGEEEFFDA & 3 & SDNSSGEFSEAI & ORP10 & 3.5 & HPPISCFYCECE & 5.2 & NPIIGETFHCSWE \\
\hline & ORP1 & 1.5 & SILSEDEFYDAI & 4.5 & SDNSSGEFSEAN & RMD2 & 3.5 & EAESEGGYITAD & 5.5 & MWRFARAYGDM \\
\hline & & & & & & RAI14 & 3.7 & ADLSFDSYHSTOT & 4 & KAFLFEKYQEAQF \\
\hline 0 & & & & & & S6A15 & 4.0 & EDAADDAFKTSE & 4 & TGLAF IAFTEAMT \\
\hline I & B. 74 other $V$ & inte & actors & & & CCNB2 & 4.0 & EENLCQAFSDALL & 4.5 & LQS INPHFLDGRD \\
\hline 0 & VPS13C & 0.0 & $\overline{\text { ESESDDEYFDAE }}$ & 3.5 & FRFNLDLYPDA & NBR1 & 4.0 & S INSQGEYEEALK & 4.5 & TCQQQEETFLLAKF \\
\hline & AKAP11 & 1.0 & SDSEVSEFFDSF & 2 & VSS IEDDFVTAF & TARA & 4.0 & WGGTSREYKESWG & 4.5 & QDNPQTSFPTCTE \\
\hline & LSG1 & 1.0 & TDEDDSEYEDCP & 3.5 & YHFDPDNFDESN & SLC25A35 & 4.0 & SSTQLCTFSSTKD & 5 & D̃QLRSLYYTDTK \\
\hline & TACC1 & 1.0 & EPEEDLEYFECSL & 3.5 & YHFDPDNFDESM & Fam118B & 4.5 & SNVRSTFFKDCLY & 4.5 & DTTFQALFLEA \\
\hline & VPS13A & 1.0 & EDDSEEEFFDAP & 3.5 & PFGLIREFSEGV & Rab3GAP2 & 4.5 & GSNPFTGFFYALE & 4.5 & AIRMẄKGYRDAQI \\
\hline & JMY & 1.5 & ETDDPEEYYESL & 3.5 & EKRDEVVYYDTY & SPB9 & 4.5 & TCQFLS TFKESC & 4.5 & KGKWNEPFDETYT \\
\hline 8 & FAM73B & 1.5 & SLTSEDSFFSAT & 4 & AEKSPKGFLESYE & KAP0 & 4.5 & PMAFLREYFERL & 5 & QGEPGDEFFIILE \\
\hline E & TubulinA1C & 1.5 & EGMEEGEFSEAR & 4 & DDSFNTFFSETGA & S26A2 & 4.5 & FCNIIPSFFHCFT & 5 & SDALLSGFVTGAS \\
\hline$\ddot{n}$ & ARFGEF12 & 1.5 & LDDSGEHFFDAR & 4.5 & RKFDSVAFGESOS & ZFPL1 & 4.5 & EPLNTSDFSDWSS & 5 & DFSDWSSFNASST \\
\hline d & SCRN1 & 2.0 & DEVQEVVYFSAA & 2.5 & PAEVGDLFYDCVD & SLC39A8 & 4.5 & RQALLFNFLSACS & 5.2 & AVLQQLNFHPCED \\
\hline & CEBPZ & 2.0 & ESDDEENFIDAN & 3 & EDVDDEEFEELI & TNR3 & 4.5 & SRCPPGIYVSAKC & 5.5 & CRDQEKEYYEPQH \\
\hline & SNX2 & 2.0 & DDDREDLFAEAT & 3.5 & LEDGEDLFTSTVS & PPIP2 & 4.7 & RSLFKGNFWSADI & 5.5 & LVGSEGAYKAAVD \\
\hline & ELYS & 2.0 & SDETTLEYQDAP & 4 & WLIDHNDYESGI & КАРСВ & 5.0 & QIVLTFEYLHSL & 5 & GSGDTSNFDDY \\
\hline & NACAD & 2.0 & SDSDSASYAEAD & 4 & ASDTYVVFGEAKI & MPRIP & 5.0 & ADQSLRYYRDSVZ & 5 & KNKSSCSFETCE \\
\hline 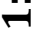 & RASF1C & 2.0 & SDSELEQYFTAF & 5 & SSTTSSGYCQED & NOL11 & 5.0 & IQTHVLSYSLCP & 5 & NAILHSAYSETE \\
\hline 0 & SPEG & 2.0 & LESSDDSYVSAC & 4 & LSVASDLYGSAF & PTN12 & 5.0 & KYRTEKIYPTATG & 5 & TPSQDSDYINA \\
\hline 疍 & ТТ39В & 2.0 & LEADEDVFEDAL & 4 & NLFLSNKFTDAL & SNX6 & 5.0 & FIWLHDSFVENE & 5 & PAPPRPDFDASF \\
\hline$\therefore$ & Aftifilin & 2.5 & NGDS,SNDFVTCN & 2.5 & DSMSDATFEESS & CTU2 & 5.0 & ILRLQTQFPSTVS & 5.5 & LVGSEGAYKAAVD \\
\hline I & SYNRG & 2.5 & EEDDFQDFQDAS & 2.5 & TDDGFTDFKTAD & NDUAC & 5.0 & LRGYLRVFFRTND & 5.7 & EMNGKNTFWDVDG \\
\hline 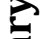 & M4K3 & 2.5 & LDSSEEIYYTAR & 3 & ELPDSDGFLDSS & NDUB3 & 5.0 & VAVGAEYYLESLN & 6 & GFAKSVSFSDVF \\
\hline I & Fam170A & 2.5 & EVTSTSEYCSCVS & 3.5 & SLSSYSSYKTCV & SNX5 & 5.0 & GVKEVDDFFEQE & 6 & PTFQSPEFSVTRQ \\
\hline I & GPN3 & 2.5 & SSMFDEYFQECQ & 4 & QYGEDLEFKEPK & CTR2 & 5.5 & STLGAGVYVLAG & 5.5 & GSAYLYTYVTVG \\
\hline 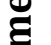 & ACBD5 & 2.5 & SDSDSEVYCDSME & 5 & LLRVIGPFYEIVE & KAP1 & 5.5 & KRKMYEEFLSKV & 5.5 & DALEPVQFEDGE \\
\hline$\overline{0}$ & TPR1 & 2.7 & DQGEEECFHDCSA & 3 & EQFKKGDYIEAES & KAPCG & 5.5 & YLYLVMEYVPGGF & 5.5 & EIILSKGYNKAVD \\
\hline a & Fam83G & 3.0 & ASSVSEEYFEVRE & 3.5 & EEEDDDDYVTLSD & NDUS4 & 5.5 & LSNMVLTFSTKED & 6 & TKEDAVSFAEKNG \\
\hline 윽 & PTPIP51 & 3.0 & STGSSSVYFTASS & 3.5 & TASSGATFTDAES & S39A9 & 5.5 & PEGVHALYEDILI & 6.5 & IRKHLLVFALAAP \\
\hline$\omega$ & RBCC1 & 3.0 & AESPESDFMSAVN & 4 & ECLTRHSYRECLG & NDUA7 & 5.5 & SHKLSNNYYCTRD & 7 & TKEDAVSFAEKNG \\
\hline & USP20 & 3.0 & RSPSEDEFLSCDS & 4 & LEDCLAAFFAADE & NDUB8 & 6.0 & KDMFPGPYPRTP & 6.5 & YNMRVEDYEPYPD \\
\hline & SNX25 & 3.2 & DKRALISFWESVE & 4 & GEIYQNFFVESKE & RASF1A & 6.5 & WCDLCGDF IWGVV & 6.5 & SVRRRTSFYLPKD \\
\hline & ZDBF2 & 3.2 & SDSPASLYHSAHD & 4 & IAKNHEEFFSNMD & NDUS6 & 6.5 & VTHTGQVYDDKDY & 7.5 & QVYDDKDYRRIR \\
\hline
\end{tabular}


Supplementary Figure 2

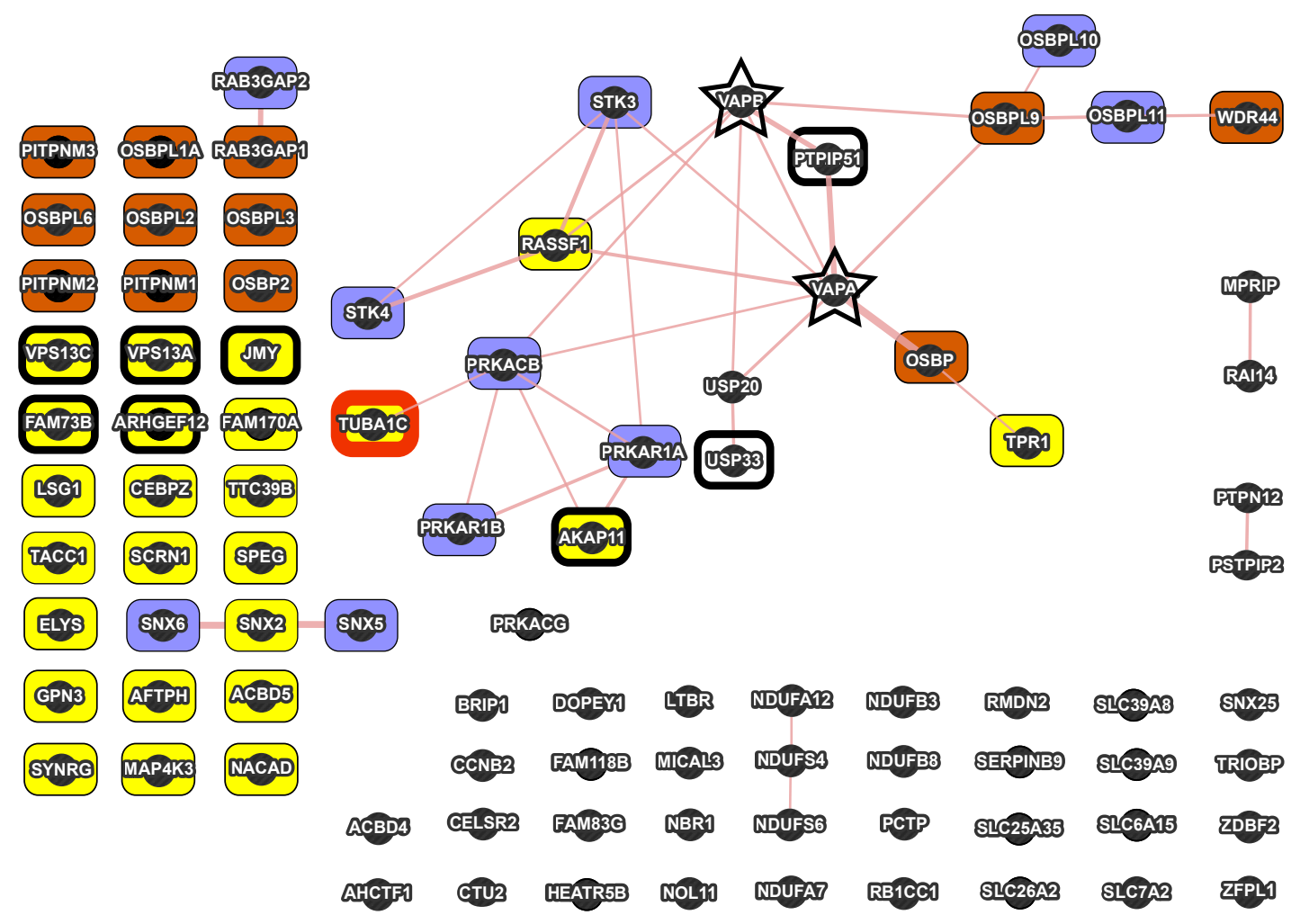


Supplementary Figure 3

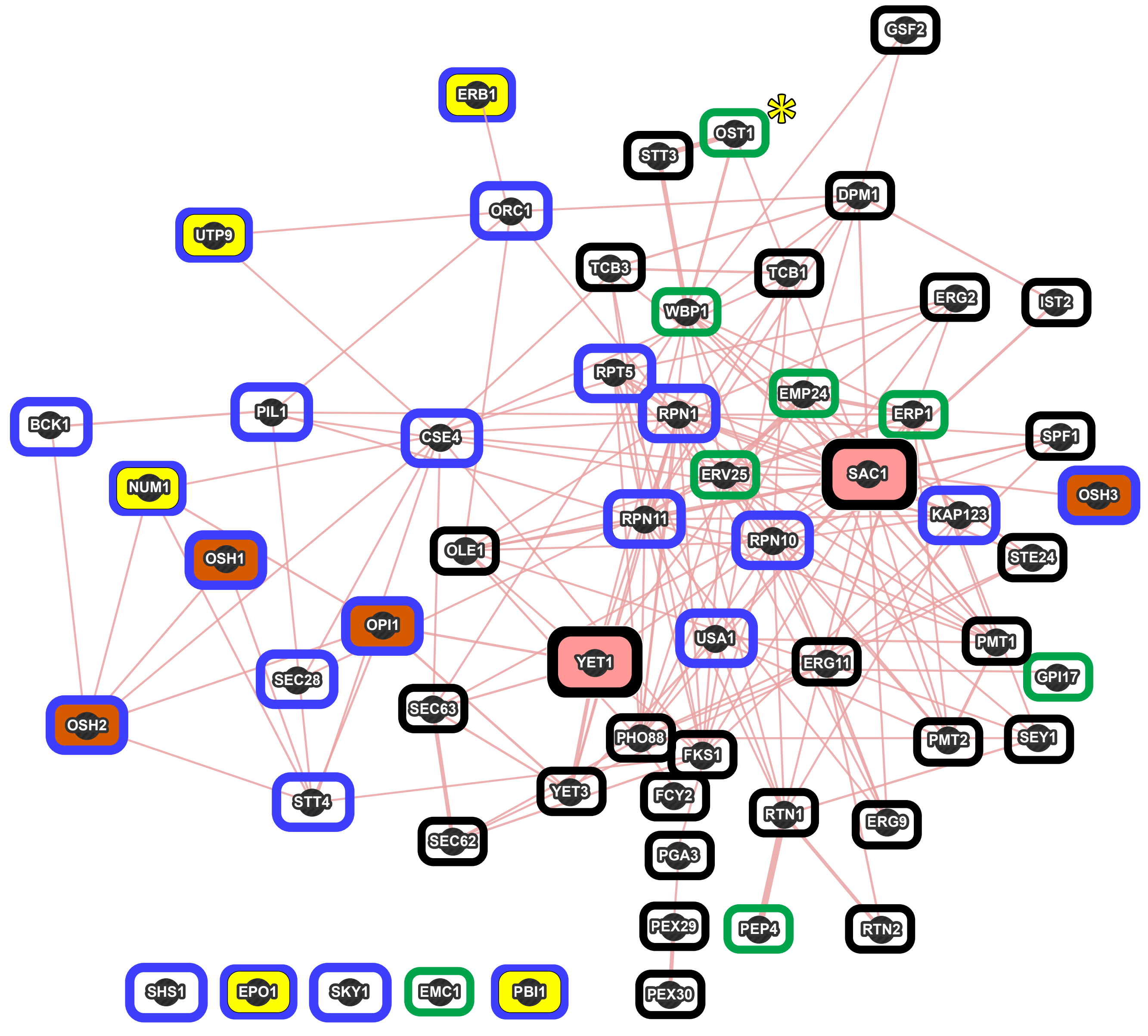

